\title{
Gaudenter Aristipo de Cirene. La índole psicosomática de las afecciones y la configuración hedonista de un proyecto virtuoso de vida
}

\author{
Deyvis Deniz Machín \\ Universidad Central de Venezuela/Universidad Simón Bolívar \\ vagonesdeltiempo@gmail.com
}

\begin{abstract}
En el ambiente del círculo socrático ${ }^{1}$, la indagación filosófica giraba constantemente en torno a la pregunta "cómo se debe vivir" ${ }^{2}$. Mezclar consideraciones epistemológicas y éticas resultaba ser la vía más idónea al momento de ofrecer respuestas filosóficamente articuladas o sencillamente justificadas.
\end{abstract}

1 “El grupo de los primeros socráticos configura un concierto de personajes sumamente disímiles, entre los que se cuentan tanto intelectuales con claras posturas propias, como otros que integraban el núcleo en calidad de allegados y transmisores [...]. A partir de los discípulos, que construyeron líneas con identidad respecto de la del maestro y sus condiscípulos, se fueron gestando movimientos teóricos más o menos institucionalizados que dieron lugar a los grupos socráticos". Mársico, C. (2013: 14) cataloga a Jenofonte, Platón y Antístenes como "los que están más a la cabeza o en la punta

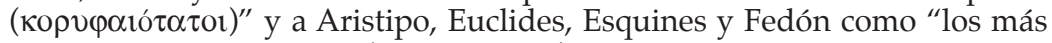
eminentes o distinguidos ( $\delta 1 \alpha \sigma \eta \mu o ́ \tau \alpha \tau o \imath) "$.

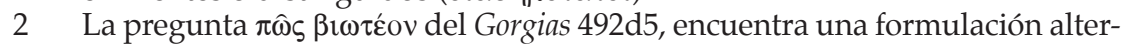

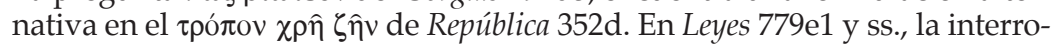
gante da paso a una exposición deontológica. En Phlb. 21d2, queda circuns-

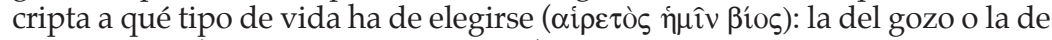
la prudencia ( viene empleada, mutatis mutandis, para hacer referencia al placer (i்oví) que, en principio, es identificado con la diosa Afrodita, Phlb., 12b. Esta dicotomía la expone Sófocles, Aj. 554-555, cuando Ayax, vuelto en sí, le dice al hijo: "en el ser prudente, en efecto, no reside la vida más placentera, hasta que te ha-

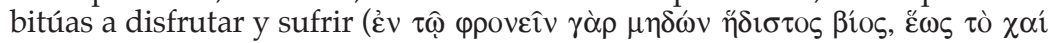

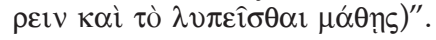


Lejos de asumirla como exclusivamente ética, la interrogante, al inquirir tanto por el sentido como por los basamentos que son inherentes a los modos de vida, demandó un abordaje filosófico en el que el $\tau \hat{\lambda} \lambda$ os o "fin humano" fue descubierto como punto de partida y, a su vez, de llegada de toda la reflexión filosófica ${ }^{3}$. La frontera entre vida teórica-contemplativa y vida práctica paulatinamente quedaba difuminada en la medida en que las posibles concepciones de lo real fueron asumidas como el marco de delimitación de los posibles estilos de vida: en todo estilo de vida concurren una serie de creencias que, al ser tenidas por buenas, válidas o útiles, en última instancia dan cuenta del conjunto de praxis que cualquier agente emprende en un momento dado. En el ámbito socrático, todo proyecto consciente de vida reclamaba consecuentemente la permanente y metódica reflexión en torno a la aclaración de las propias creencias en el convencimiento de que, como se apunta en la Apología, "una vida desprovista de examen no merece la pena ser vivida" ${ }^{4}$. Aristipo hizo suya esta enseñanza, quizá emulando al Sócrates histórico ${ }^{5}$,

3 Aristóteles recalca, Metafísica 987b \& $1077 \mathrm{~b} 17$ y ss., que Sócrates se ocupó de

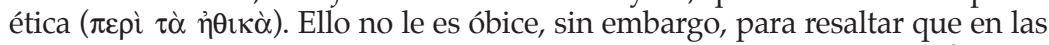
cuestiones éticas buscaba por medio de razonamientos lo universal ( $\tau$ ò $\kappa \alpha$ -

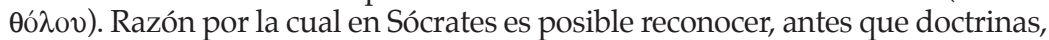
dos elementos metodológicos que son constitutivos del conocimiento cientí-

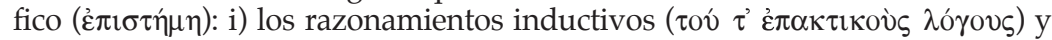

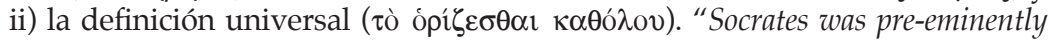
a masterly debater, clear-sighted in tracking down a problem to its simplest terms, ruthless in exposing a fallacy" (Tarrant, 1932: 152). Más reciente, Nozick (1995: 143155) ve la figura de Sócrates no sólo como proponente de un método de investigación, sino como "encarnándolo" (as embodied in Socrates).

4 Pl. Ap. 38a5-6.

5 "Siendo interrogado sobre cómo murió Sócrates, dijo, así como yo hubiera deseado" (Mann, 1996: 111). "There seem to be at least three important ways in which Aristippus can be seen directly motivated by Socrates. First of all, Socrates too belongs among those philosophers whose life was meant to be a radical challenge [...]. Aristippus takes up this dimension of Socrates' life, albeit in a very different way". 


\section{al convertir su estilo gaudenter de vida o $\pi \mathrm{o} \lambda \nu \tau \varepsilon \lambda \hat{\omega} \varsigma \zeta \hat{\eta} v^{6}$ en un proyecto filosóficamente examinado en el que "homolo- gó, según transmite Ateneo, doctrina y vida"7.}

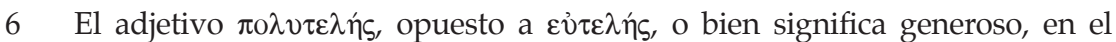
sentido de pródigo o costoso, o bien suntuoso. En este segundo sentido lo emplea Platón, Hp. Mi. 368c7, para referirse al característico estilo suntuoso de los Persas. En el primer sentido lo emplea en grado superlativo, R. 507c7, probablemente en tono irónico-crítico, para señalar que entre los sentidos la visión es sumamente pródiga ( $\pi 0 \lambda v \tau \varepsilon \lambda \varepsilon \sigma \tau \tau \dot{\alpha} \tau \eta v)$, aun cuando sin la luz ( $\varphi \hat{\omega} \varsigma)$, el tercer elemento, la visión no ve - la facultad no actúa- y los colores son invisibles - las cualidades no son percibidas por la facultad-. Dos testimonios pueden ser señalados a fin de iluminar la actitud pródiga de Aristipo. En el primero, gnom. vat. 743 n. 40, Platón reprocha al de Cirene haber gastado doce dracmas en un pescado costoso $(\pi \circ \lambda v \tau \varepsilon \lambda \hat{\eta} i \chi \theta \hat{v} v)$. Aristipo le preguntó si él hubiera comprado el mismo pescado en caso de que costara un dracma. Al estar Platón de acuerdo, Aristipo dijo que para él no costó mucho. Así, lo que es un dracma para Platón, son doce para Aristipo. En el segundo, D.L. II 75 , no queda identificado quién le reprocha el gasto en la compra de pescado

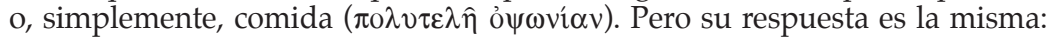
“ ¿tú no los comprarías por tres óbolos? Dado que el fulano asintió, Aristipo dijo: no es, entonces, que yo soy amante del placer ( $\varphi \imath \lambda \hat{n} \delta$ ovos), sino que tú eres avaro ( $\varphi \imath \lambda \alpha \dot{\alpha} \rho \gamma \nu \rho \varsigma))^{\prime \prime}$. La anécdota viene presentada de forma similar, Athen., VIII 343, con la salvedad de que Aristipo niega ser un degustador exquisito

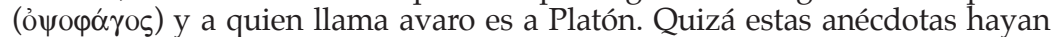
sido extractadas del Contra quienes le reprobaban por comprar pescado pródigamente, uno de los veinticinco diálogos que le son atribuidos en uno de los dos catálogos de los que Diógenes da noticias, D.L. II 84-85. Propiamente, en relación con la expresión $\pi 0 \lambda v \tau \varepsilon \lambda \hat{\omega} \zeta \zeta \hat{\eta} v$ pueden ser señalados dos pasajes. En el primero, D.L. II 68, Aristipo, a uno que le reprochaba vivir suntuosamente, le contesta: "si fuera malo ( $\varphi \propto \hat{v} \lambda \mathrm{ov})$, no hubiera tenido lugar en las celebraciones de los dioses". En el segundo, D.L. II 69, Platón es quien le reprocha. Una vez que Platón le concedió a Aristipo que Dionisio era bueno ( $\alpha \gamma \alpha \theta$ ós) y vivía de un modo más suntuoso que el suyo ( $\pi \mathrm{o} \lambda \nu \tau \varepsilon \lambda \varepsilon \dot{\varepsilon} \sigma \varepsilon \rho \rho v)$, le contestó éste: "nada

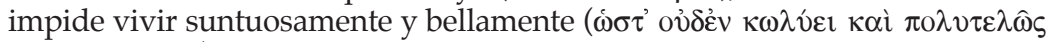

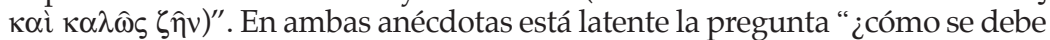

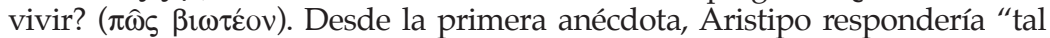
como viven los dioses", mientras que desde la segunda la respuesta sería bellamente, tomando el adverbio en su dimensión estética y ética. Platón y los demás socráticos objetarían poco a estas respuestas a no ser que ambas vienen identificadas en la filosofía de Aristipo con el modo $\pi \circ \lambda v \tau \varepsilon \lambda \hat{\omega} \varsigma$ de vivir.

7 Athen. XII 544b, "homologó doctrina y vida, la cual vivió en [medio de] toda

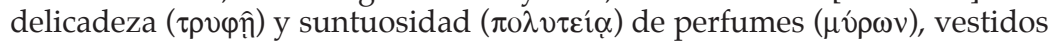

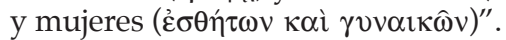




\begin{abstract}
A Platón debemos la primera objetivación del placer, esto es, la primera exposición argumentada que buscó delimitar la esfera de lo placentero a través de una taxonomía jerárquicamente fundada ${ }^{8}$. El placer y lo placentero, no obstante, en tanto hecho objetivo de la subjetividad, había encontrado con anterioridad e igualmente encontrará con posterioridad a él, exposiciones alternativas que, si bien en ningún caso podrán ser enaltecidas como legítimas o representativas del mundo griego, tampoco debieran ser tomadas como ilegítimas o inauténticas a la luz de la filosofía de Platón ${ }^{9}$. Con base en la doxografía existente, queda cla-
\end{abstract}

$8 \quad$ Acá tenemos especialmente presente los planteamientos de la República IX y Filebo, sin desconocer que el placer fue constantemente abordado por Platón en otros diálogos. Concordamos con Russel (2005: 9) cuando cataloga la posición de Platón en relación con el placer en términos de "pleasure as a conditional good"; sin embargo, esta calificación, privilegiando la lectura evolutiva, no queda exenta de críticas de parte de quienes han tomado a Platón como un filósofo antihedonista e incluso por parte de aquellos que han abogado por el hedonismo de Platón. Con Bravo (2003), es posible sostener que para explicar el hecho placentero se ha de tomar en cuenta consideraciones físicas, fisiológicas, psicológicas, ontológicas y epistemológicas que están íntimamente ligadas al hecho placentero. Por ello, algunos diálogos favorecen lecturas de corte hedonista o utilitarista, v.g. Hipias mayor o Protágoras, y algunos otros, en cambio, favorecen la lectura antihedonista, v.g. Gorgias o Fedón. Como apunta Wolfsdorf (2013: 40-41): "Plato's various treatments differ because he pursues different questions or problems relating to pleasure in different contexts [...] in each dialogue he creates what may be called a 'favored character' to serve as the philosophical protagonist".

9 Wolfsdorf (2013: 3) señala que el tópico del placer entra en la tradición filosófica griega en el siglo $\mathrm{V}$ a. C. a partir de dos corrientes intelectuales: la ética y la fisiológica. Si bien la segunda corriente es algo más restringida al incluir mayoritariamente lo que, en principio, cae bajo la categoría de "filósofos presocráticos", la primera es, por su parte, lo bastante laxa como para admitir también la inclusión de la poesía. La poesía gestó la delimita-

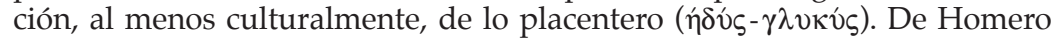
en adelante lo placentero viene principalmente asociado tanto al banquete: comida, música y danza, v.g. Il. XIV 509 y ss., como preeminentemente a Afrodita y Eros, de quien Safo dice, fr. 130, valiéndose del calificativo homérico del sueño, que "afloja los miembros ( $\lambda v \sigma \mu \varepsilon \dot{\lambda} \eta \varsigma)$ " y al que Anacreonte, XIII, describe como "arrojándose él mismo al verse en apuros al ya no tener 


\section{ro que los socráticos debatieron sobre el placer ${ }^{10}$; buscaron definirlo, clasificarlo, pero, más relevante aún, problema- tizaron sobre cómo habría de ser incorporado en la con- secución de un proyecto virtuoso de vida ${ }^{11}$. El debate, sin}

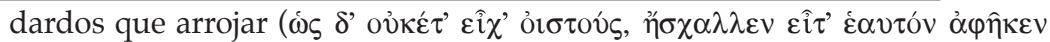
$\varepsilon i \varsigma \varsigma \beta \varepsilon ́ \lambda \varepsilon \mu \nu 0 v)$ ). “¿Qué vida, qué deleite sin la dorada Afrodita?”, se pregunta Mimnermo, fr. 1. Para quienes no hallaban manera alguna de dar una respuesta, la salida ofrecida era subir a la roca Léucade y "zambullirse ebrio de

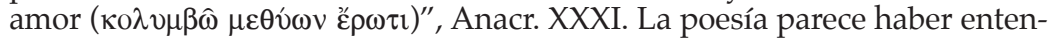
dido y celebrado el placer en tanto "encantadoras flores de la juventud (oi

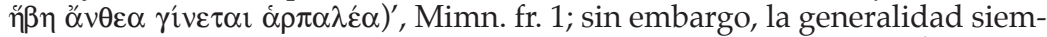
pre encuentra excepciones. Así, encontramos a Arquíloco, fr. 328, haciendo

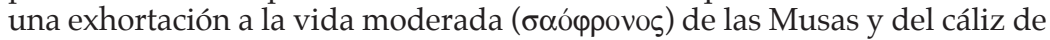
vino, reconociendo que en esa hay deleite ( $\tau \dot{\varepsilon} \rho \psi 1 \varsigma)$, dicha genuina ( $\chi \alpha \rho \alpha ́$ ) y "placer por naturaleza ( sazón a sus vidas con lo que califica como "placeres vergonzosos ( $\alpha i \sigma \chi \rho \hat{\imath} \imath$

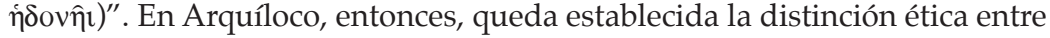
placer por naturaleza y placeres vergonzosos. Jenófanes, fr. 1, quien caería bajo las dos categorías por ser a la vez poeta y "filósofo presocrático", entiende que "no es hybris beber, siempre que, no siendo muy anciano, con la cantidad bebida se pueda volver a casa sin criado". Demócrito, depositando

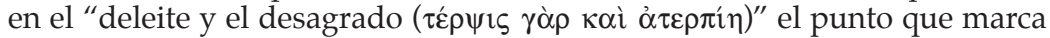
la frontera entre lo ventajoso y lo que no lo es, entiende que "bueno y verdadero es lo mismo para todos los hombres; placentero, en cambio, para cada

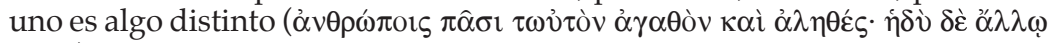
$\left.\alpha \dot{\alpha} \lambda \lambda_{0}\right)^{\prime \prime}$. Enmarcado en estos antecedentes, es posible sacar a relucir un aspecto capital de la postura hedonista de Aristipo, pues conforme al testimonio de

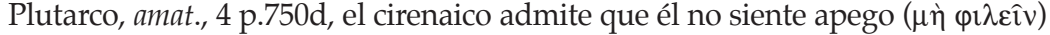
por el vino y el pescado, sino que "hace uso placenteramente de cada uno ( $\dot{\alpha} \lambda \lambda$ '

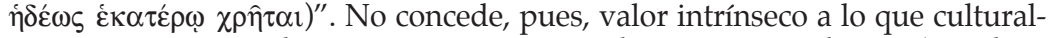
mente se tiene por placentero, sea esto natural, para expresarlo con Arquíloco o vergonzoso. El planteamiento, por el contrario, coloca el peso en el sujeto que sirviéndose del objeto del placer experimenta placer, no por el hecho de que en el objeto del placer haya algo de placentero en términos absolutos, sino porque el sujeto al hacer uso del objeto del placer se dispone placenteramente al "sacar como fruto placer y disfrute ( rostro, un cuerpo, un vino o sencillamente de un pescado.

10 (Boys-Stones y Rowe, 2013: 28-29), "There is no question that members of the Socratic circle thought that the most important truths to be sought were those concerning ethics. Ethics constitute the dominant subject of their researches, and the revolutionary approaches in this field no doubt constituted the most distinctive collective feature of their discussions [...] One of the major topic of discussion and disagreement under this heading (v.g. What is 'good' for a human being? What constitutes a good human life?) was the role of pleasure in the good life".

11 Pl., Phlb. 19b2-3. "Me parece, en efecto, que ahora -dice Protarco- Sócrates nos pregunta sobre las clases ( $\left.\varepsilon^{\imath} \delta \eta\right)$ de placer: bien si hay o no, cuántas hay 


\section{embargo, no arrojó como resultado una propuesta unitaria o siquiera compatible entre los miembros del grupo. Aristipo, ciertamente, defendió sin ambages el placer $^{12}$. Ahora bien,}

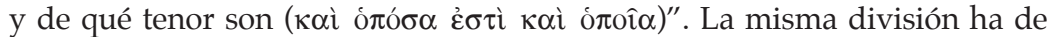

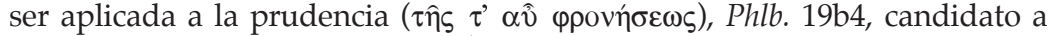

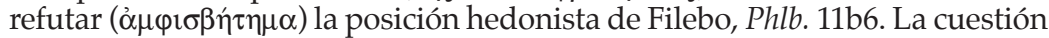
es capital, pues no sólo revela qué concepción del bien y de los bienes particulares que participan de aquel, para decirlo con Platón, defiende cada interlocutor, sino que a la par posibilita la discusión en torno a la vida buena, esto es, permite que progresivamente sean ofrecidas respuestas a la pregunta qué vida se debe elegir. En este sentido, placer-prudencia, extremos de la reflexión dialéctica, encuentran también una expresión biológica. Así, a la

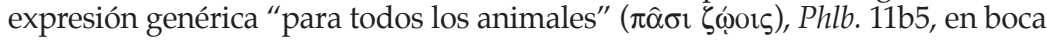
de Filebo, Sócrates repone que se trata, entonces, de averiguar qué "estado

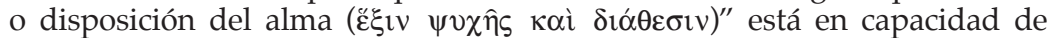
suministrar o garantizar la "vida feliz para todos los hombres ( $\alpha v \theta \rho \omega \pi \circ \iota \varsigma \pi \hat{\alpha} \sigma \mathrm{\imath}$

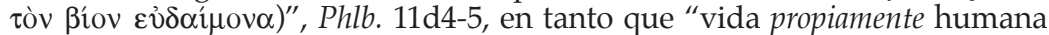
( $\alpha v \theta \rho \omega ́ \pi$ ov ßíov) y no propia de un pulmón o de cuantos seres animados con

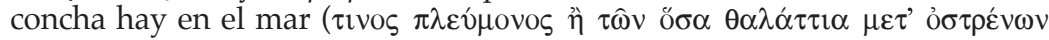

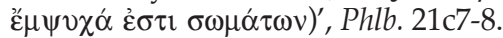

12 “Aristipo de Cirene. Siendo ése goloso y amante del placer ( $\varphi \imath \lambda \hat{n} \delta$ ovo $)$ dijo que el telos del alma es el placer. Quien experimenta placer, según dice, es feliz; quien, en cambio, no experimenta placer alguno es tres veces desdi-

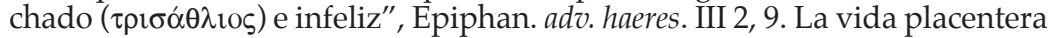

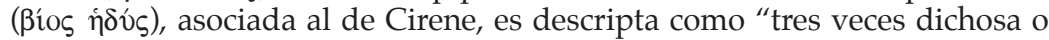

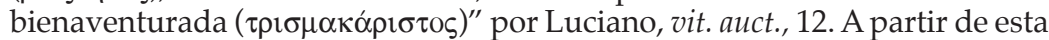
voz, que constituye un hápax, y de los testimonios ahora citados es posible entrever la tensión dicotómica entre vida placentera, tres veces dichosa, y vida sin placer $(\mu \eta \delta, \circ \nu \omega \varsigma)$, tres veces desdichada, sin necesidad de acudir a

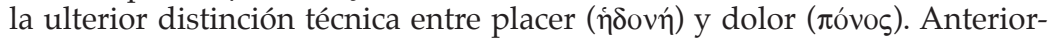
mente fue señalado, n. 8, que Aristipo no se reconocía amante del placer ( $\varphi \imath \lambda \hat{n} \delta$ ovos). Conviene, pues, precisar el calificativo de "goloso ( $\gamma \alpha \sigma \tau \rho^{\prime} \mu \alpha \rho-$

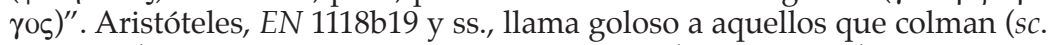

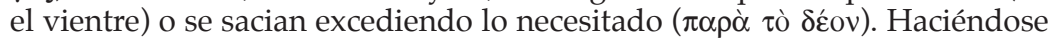

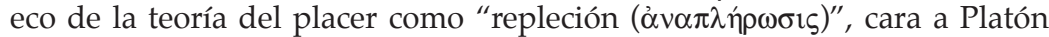
y que quizá tenga en Empédocles a su iniciador, DK 31 A95, Aristóteles censura tal comportamiento, destacando que el "exceso ( $(\pi \varepsilon \rho \beta \rho \lambda \eta \dot{)}$ " en los placeres es "intemperancia $(\dot{\alpha} \kappa \circ \lambda \alpha \sigma i \alpha)$ ". El exceso marca la característica principal de la intemperancia. Conforme al testimonio de Estobeo, Stob. III 37, 24, sabemos, sin embargo, que Aristipo, una vez "interrogado sobre qué es digno de admiración en la vida, dijo, un hombre ecuánime y moderado

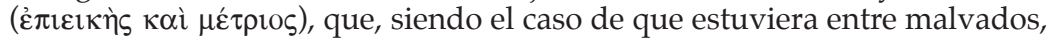
no se corrompe". La anécdota viene replicada puesta en relación con Platón en ocasión de un banquete en la corte de Dionisio. Aristipo, apelando a unos versos de Eurípides ante la negativa de Platón a colocarse un vestido femenino, le habría dicho que quien es "sensato ( $\sigma \omega \dot{\varphi} \varphi \omega v)$ " no se corrompe aun estando en medio de fiestas báquicas, Athen. XII 5444b \& Suda. 
en qué medida y a partir de qué clase de parámetros interpretativos la filosofía denominada cirenaica ${ }^{13}$ pudo haber extraído sus fundamentos ético-epistemológicos de las tesis o, digamos mejor, del modo gaudenter de vida que la tradición doxográfica ha mayoritariamente atribuido al controvertido miembro del círculo socrático es un punto que aún genera discrepancias entre los intérpretes ${ }^{14}$. De suerte que, si bien es cierto que la doxografía imposibilita la defensa de una visión monolíticamente unificada alrededor de un corpus filosófico, doctrinalmente cimentado e iniciado por un maestro, no obstante, igualmente cierto es que la articulación contextualizada de los testimonios sí permite establecer lo que podríamos denominar la índole y propensión de los cirenaicos, Aristipo incluido ${ }^{15}$. En consecuencia, tanto el carácter

13 Dos ramas de cirenaicos surgieron de dos de sus discípulos inmediatos: Arete, su hija, y Antípatro, coterráneo suyo. De Arete sale, en primer lugar, Aristipo, su nieto, quien es tomado por la mayor parte de los intérpretes como el articulador e incluso creador de las tesis cirenaicas, y de él sale, a su vez, Teodoro, apodado el ateo; de Antípatro, por su parte, salen Parébates, y de éste Hegesias y Anniceris. La tradición doxográfica hace referencia a ellos

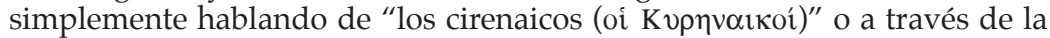

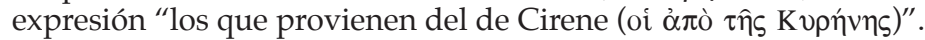

14 (Zilioli, 2012: 173): "By Cyrenaic philosophy I mean a coherent set of philosophical views (ethical, epistemological, metaphysical and semantics). I say that the set of philosophical views I see as representing Cyrenaic philosophy is coherent because I take Cyrenaic ethics to be perfectly organic with the epistemology and metaphysics of the school, as much as epistemology and metaphysics are in perfect accordance with the semantic approached adopted by Cyrenaics". Contra este punto de vista ya Giannantoni, G., op. cit., p. 71, advertía que "Le stesse oscillanzioni che in materia de gnoseología, di lógica e perfino di etica noi riscontreremo nella dossografia cirenaica obbligano a suporre una molteplicità di indirizzi e a rinunciare all'idea, fatta prevalere dallo schematismo degli autori di Successioni, che Aristippo abbia fondato una vera e propria scuola filosofica". La posición más escéptica al respecto es la de Mann, W-R., art. cit., p. 119, quien considera que más allá del estilo de vida de Aristipo no hay tal cosa como la filosofía de Aristipo. "Aristippus should not be assimilated to the Cyrenaics, that his project of leading a certain kind of life not only need not, but cannot be given a theoretical foundation".

15 Str. geogr., XVII 3, 22, "Hubo ilustres hombres de Cirene, por ejemplo, Aristipo, el socrático, quien, sin duda, puso los cimientos de la filosofía cirenaica". 
fenoménico ${ }^{16}$ como la orientación hedonista de los cirenaicos dan inicio con las enseñanzas del discípulo de Sócrates: su estilo de vida traslucía una concepción de lo real que, si bien pudo haber sido plasmada por escrito, y lo fue ${ }^{17}$, antes bien fue encarnada y transmitida mediante el ejemplo aleccionador del propio ejercicio de vida ${ }^{18}$. Aristipo estaba consciente de que, como aún suele decirse, con el ejemplo se enseña.

Da cuenta de ello, pese a la abierta animadversión, la palpable distorsión terminológica y, en casos, la caricaturizada exageración, el puñado de anécdotas que la tradición historiográfica nos ha legado ${ }^{19}$. Luciano de Samosata es, con mu-

16 Tres testimonios dan pie a tres posibles etiquetas, a saber.: i) a la luz de Eusebio, PE.,. XIV 19,1 764b, los cirenaicos serían escépticos-relativistas, ii) a la luz de Sexto, $P$. I. 215, serían dogmáticos-débiles, mientras que iii) a la luz de, M., VII 190-196, serían fenoménicos-perspectivistas.

17 D.L. II 84-85. Diógenes presenta dos catálogos de obras que aparentemente son levantados a partir de cuatro fuentes. En primer lugar, y sin especificar de quién proviene la información, se señala la composición de un total de veinticinco diálogos, unos escritos en ático y otros en dórico, junto con una obra sobre Libia en tres libros. Seguidamente, se añade a través de un genérico "algunos" que le son de su autoría seis libros de diatribas con el matiz inmediato de que, según "otros", entre los que se cuenta Sosícrates de Rodas, Aristipo no habría escrito nada. Finalmente, basado en Soción de Alejandría y Panecio de Rodas, es señalado un segundo catálogo de obras de las que es posible resaltar, en primer lugar, la ausencia de diálogos; en segundo lugar, la coincidencia con la segunda fuente en torno a los seis libros de diatribas y, en tercer lugar, propiamente los títulos de las obras, pues destacan un Acerca de la educación, un Acerca de la virtud, un Protréptico, una obra dirigida a Lais, su compañera, y otro a Sócrates. Ahora bien, es cuestión debatible si Aristipo puso su pensamiento por escrito con la intención de dejar a sus discípulos las lecturas útiles en un corpus. A la luz de los testimonios, sólo es posible establecer algunas conjeturas. G. Giannantoni, op. cit., p. 61: "Solo per congettura si possono far risa-

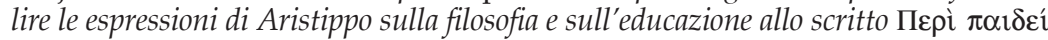
$\alpha \varsigma$, quelle sul piacere e la ricchezza allo scritto Пврі̀ $\alpha \rho \varepsilon \tau \hat{\varsigma} \varsigma$, quelle su Socrate allo

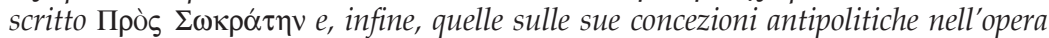

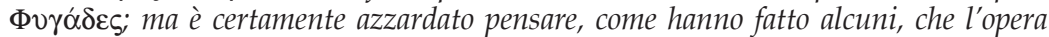
su Socrate fosse addirittura dedicata ad una revisione del pensiero del maestro". (Ver Mannebach, 1961: 80-84).

18 D.L 72: "permanentemente aconsejaba a su hija Arete de la mejor manera, enseñándole mediante el ejercicio a despreciar el exceso".

19 (Decleva, 2009: 130): "Because he became in antiquity the representative par excellence of a life devoted to pleasure, his biography is full of stories and jokes based on 
cho, el mejor ejemplo de esto último. En Doble acusación o los tribunales Aristipo aparece ante el Areópago, siendo reclama-

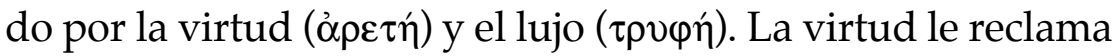

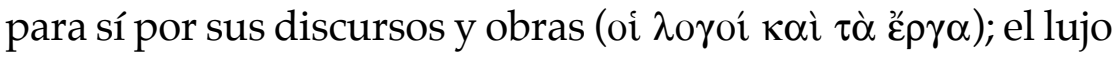
replica, sin embargo, que es obvio que le pertenece en razón de las coronas, la vestimenta y los perfumes ${ }^{20}$. De la caricatura es posible extraer la proyección de la ambigua imagen lujosamente virtuosa o, si se quiere, virtuosamente lujosa que engalanó al discípulo de Sócrates. En el ambiente socrático, tal proyecto no encontró eco. Antístenes, Jenofonte y Platón le combatieron en tanto que un "estilo de vida muelle

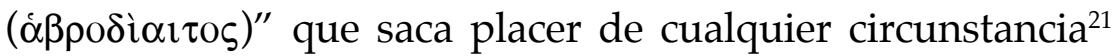
no luce, en manera alguna, virtuoso ${ }^{22}$.

this characteristic. Nevertheless, if the fictional encrustations are stripped away to reveal the historical core beneath, a 'Socratic' figure emerges who is not so heterodox with respect to the master as he might seem".

20 Lucianus, bis acuss. 23. En la gradación de los placeres corporales que vienen asociados a la templanza y la incontinencia ( $\sigma \omega \varphi \rho о \sigma u ́ v \eta-\alpha ́ \kappa o \lambda \alpha \sigma i \alpha)$, Aristóte-

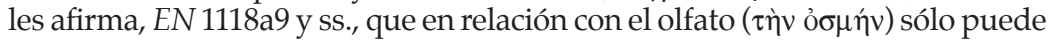
hablarse de incontinencia por accidente $(\sigma \nu \mu \beta \varepsilon \beta \eta \kappa o ́ \varsigma)$. En tal sentido, se ha de notar que el énfasis viene puesto no tanto en el hecho de experimentar placer a través del olfato, sino más en el objeto del placer que causaría la experiencia de placer en el órgano sensorial del percipiente. Así, "no son considerados intemperantes quienes se deleitan con los olores de las mieles, rosas o inciensos, sino especialmente quienes lo hacen con los perfumes y las comidas refinadas (sc. pescado)". Es aventurado precisar si Aristóteles está pensando o no en Aristipo, a sabiendas de que las veces que lo menciona explícitamente sólo lo hace considerándolo sofista y no hedonista; sin embargo, si él hubiera tenido que hacerse un juicio en función de la doxografía que nos ha sido transmitida como perteneciente al de Cirene, hubiera visto en Aristipo al prototipo de intemperante por accidente.

21 Lucianus, vit. auct., 12. Luego de describir la vida como tres veces dichosa o bienaventurada, $c f r$. n. 14, Luciano resume el "punto capital de la filosofía de

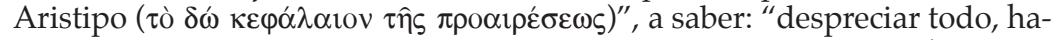

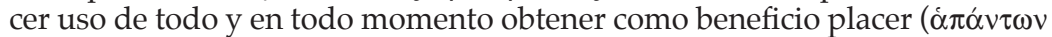

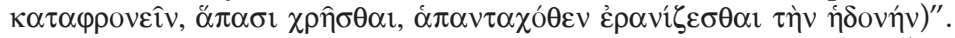

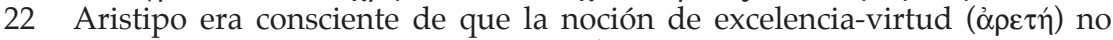
pasa por convenciones culturales; no hay ungüento o vestimenta que sirva de impedimento alguno al momento de ser y conducirse virtuosamente en la vida. Clemente, paedag. II, VIII 64,1, “Un caballo no es dañado en la excelencia-virtud propia del caballo por estar ungido con perfume, tampoco un 
$* *$

La filosofía de Aristipo giró en torno al reconocimiento de

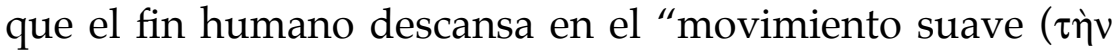

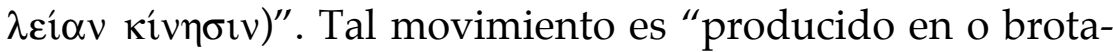

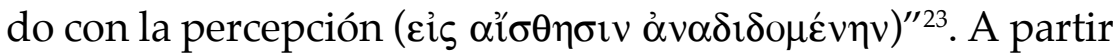
de esta sentencia, sus seguidores, entre los cuales se cuentan su hija y su homónimo nieto ${ }^{24}$, desarrollaron y articularon lo que, sin duda, se erigió como la primera filosofía hedonista de occidente. De ella, sin embargo, apenas tenemos noticias. Reconstruir sus postulados ético-epistemológicos no pasa por desmentir a priori la doxografía disponible ${ }^{25}$; por el contrario, el esfuerzo exegético ha de poder contribuir a la contextualización del planteamiento filosófico de Aristipo que, lejos de revelar una tosca grosería ${ }^{26}$, evidencia originalidad y actualidad filosófica ${ }^{27}$. Ello también contribuiría a esclarecer co-

perro lo hace en la excelencia-virtud que es propia del perro por haber sido perfumado. Tampoco, entonces, el hombre". Clemente, a pesar de catalo-

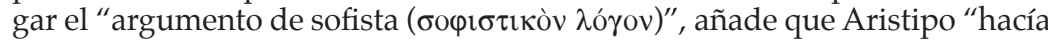

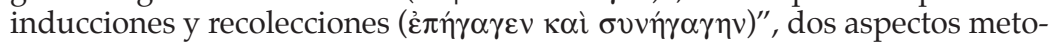
dológicos del pensamiento de Platón, el último de los cuales al ver de Bravo, F. (2002: 143), no se ha de confundir con el estadio refutatorio de Sócrates). "Pero no debe confundirse esta primera fase de la etapa 'indagatoria' (que se halla en los límites de la observación y la experiencia) con la reunión (synagoge) del método plátonico del Fedro y del Sofista (que se caracteriza por un acto sintético del espíritu)".

23 Loc. cit.

24 Cfr. n. 15.

25 Diógenes Laercio es, con frecuencia, víctima de este proceder.

26 La expresión es de Guthrie, W.K.C. (1969: 465). Al respecto, Tsouna, V. (1994: 381): "Traditionally he is depicted as one of the most minor figures of the Socratic circle -someone whose questionable charm consists in vulgar wit, social rudeness, opportunism, and unscrupulousness. However, there are some indications that such a portrayal is unfounded".

27 Morgado, I. (2012: 74): “La interocepción es el sentido del estado fisiológico del cuerpo, el que hace que nos sintamos cómodos o incómodos, confortables o con malestar, cansados o descansados, relajados o estresados, sanos o enfermos [...]. Como ya insinuamos, las sensaciones viscerales (sc. emociones) resultan también muy importantes para la autoconciencia y la percepción que tenemos de estar ubicados en nuestro propio cuerpo. Todo lo dicho convierte al sentido interoceptivo en un determinante crítico del com- 
lateralmente el debate filosófico de los miembros del círculo socrático y, por ende, arrojaría luz sobre la figura de Sócrates, al menos a nivel doctrinal.

Según testimonia Aristocles de Mesina, Aristipo, el

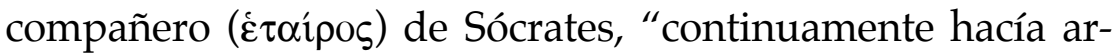
gumentaciones sobre el placer" 28 ; sus seguidores, entonces, sospecharon que para él el fin humano consistía en "vivir placenteramente ( $\tau$ ò $\dot{\eta} \delta \dot{\varepsilon} \omega \varsigma \zeta \hat{\eta} \nu$ )"29. Tal modo placentero de vida, por sorprendente que luzca, no se alcanza -entendieron los cirenaicos- a través de la riqueza o del desenfreno ${ }^{30}$, sino del

portamiento humano, algo, como ya hemos dicho, que no siempre consideramos cuando hablamos de los sentidos". Sobre la dimensión exteroceptiva e interoceptiva de los sentidos, esto es, de la percepción, escribiré en seguida puesto en relación con el planteamiento del Cirenaico.

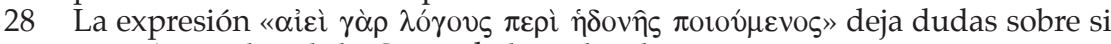
para Aristocles el de Cirene habría dejado o no por escrito sus posiciones filosóficas o si sólo se trataba de disertaciones destinadas a ser escuchadas. Para Aristocles, véase Chiesara, M. (2001).

29 Esta formulación, aun cuando no necesariamente contradice la presentación del discípulo de Sócrates, pues pone el énfasis en la diátesis del sujeto, es con toda probabilidad del nieto de Aristipo, a la que añadía que se trataba del

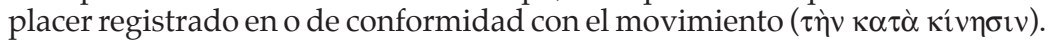
Si tener que abordar acá la distinción entre placeres cinéticos y catastemáticos o estacionarios, es posible afirmar que el nieto de Aristipo tenga presente el

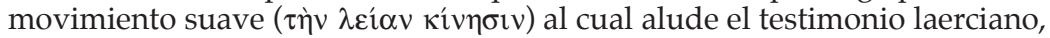
loc. cit. Aun así, resulta oportuno tener presente que Platón, $R$. 583b y ss.,

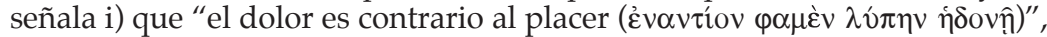
ii) "entre ambos hay un estado intermedio que denomina tranquilidad

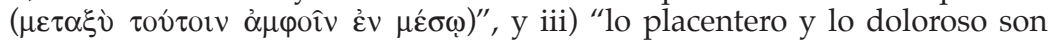

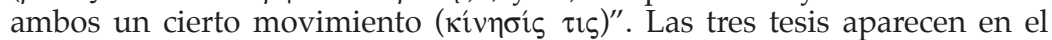
planteamiento del nieto de Aristipo y frecuentemente son tomadas como reformulaciones o innovaciones que habrían sido hechas con el propósito de brindar robustez al pensamiento de Aristipo. Si así fuera, llamar la atención sobre una posible influencia no resulta fuera de lugar. Otra lectura es ver en este pasaje así como en tantos otros de Platón la propia filosofía de Aristipo. Hay testimonios que avalarían una y otra lectura.

30 D.L. II 69: “al preguntarle Dionisio por qué razón los filósofos acostumbran a marchar a las puertas de los ricos, pero los ricos jamás a las puertas de los filósofos, dijo: «es porque unos saben de qué necesitan, mientras que los otros no lo saben»". D.L. II 72: “Al ser preguntado por un fulano en qué sería mejor su hijo una vez fuera educado, «y si no en alguna otra cosa, dijo, al menos en el teatro a no sentarse como piedra sobre piedra». A uno que le había entregado al hijo [para educarlo] le reclamó quinientas dracmas. Al decirle aquel «con tal suma 
tomar conciencia de que "las afecciones solas son aprehensi-

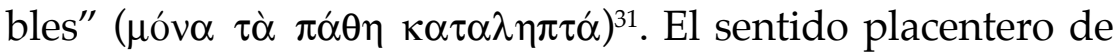
vida viene delimitado por una concepción de lo real que asume la temporalidad y la sensibilidad como elementos indispensables para su configuración ética. Ambos postulados, siendo reconducibles tanto hacia la tesis cinemática central como al propio tenor de vida de Aristipo ${ }^{32}$, evidencian la indisoluble imbricación existente entre epistemología y ética: entre con-

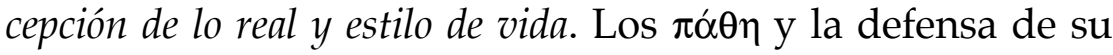
exclusiva aprehensibilidad replantearon el intelectualismo socrático-platónico desde una perspectiva íntimo-subjetiva que renunció, por un lado, en el plano epistemológico a dar cuenta y hablar asertivamente del mundo exterior ${ }^{33}$ para,

puedo comprarme un esclavo», «cómpralo, dijo, y tendrás dos»". D. L. II 73: "Ufanándose uno por beber mucho y no emborracharse, también eso, dijo, lo hace una mula»".

31 Eus., PE. XIV 20, 13 p. 768c. En líneas generales, las bases éticoepistemológicas de los cirenaicos fueron planteadas en los siguientes términos: “los que, por tanto, mantuvieron -transmite Diógenes. D.L. II 86el modo de vida ( $\tau \hat{\eta} \varsigma \dot{\alpha} \gamma \omega \gamma \hat{\eta} \varsigma)$ de Aristipo, y fueron denominados cirenaicos, se sirvieron de las siguientes opiniones. Ponían como base dos afecciones

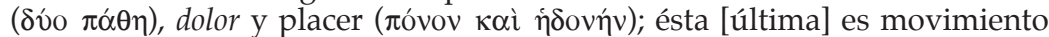

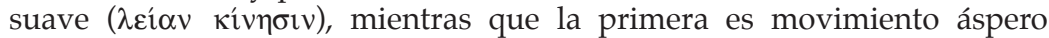
(

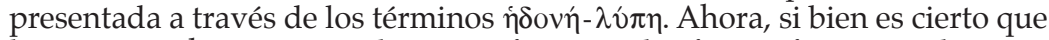
la voz $\pi$ óvos hace principalmente referencia al esfuerzo físico, no obstante, en el planteamiento cirenaico se destaca el aspecto de sufrimiento que va aparejado a todo esfuerzo y que en cuanto tal se opone, por tanto, al placer. Adicionalmente, la presentación en estos términos pudiera estar haciéndose eco del debate acerca de la virtud y la vida buena entre Aristipo y Antístenes,

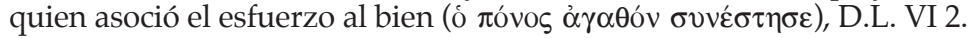

32 Como si se tratare de una caracterización teatral, Diógenes, D.L. II 66, hace ver uno de los signos distintivos del carácter de Aristipo, a saber: "representaba proporcionadamente su papel en cualquier circunstancia $(\pi \rho \circ \omega \hat{\omega} \pi \omega$,

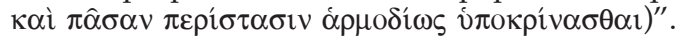

33 Los cirenaicos no encuentran incomodidad epistemológica en defender que los entes del mundo son entendidos como agentes que, puestos en contacto con el sujeto percipiente, causan cierto impacto, esto es, afecciones $(\pi \alpha \dot{\theta} \theta \eta)$, en el percipiente, permaneciendo éstos, sin embargo, impenetrables de forma asertiva para el sujeto que los percibe. El compromiso de objetividad pasa sólo por lo lógico-lingüístico en la medida en que no se pretende objetividad 
consecuentemente, postular como bien en el plano ético no la $\varepsilon v ̉ \delta \alpha \iota \mu$ oví $\alpha$ sino el placer ${ }^{34}$, dejando así trastocado decididamente la dimensión temporal del proyecto ético, dado que el énfasis vendrá puesto no sobre la línea de tiempo que representa -permítaseme ejemplificarlo de este modo- un proyecto de vida, sino más bien en la permanente atención a la

más allá de los límites del percipiente. Puesto de otro modo, toda pretensión de objetividad reconoce los límites de la experiencia. Así, la respuesta a la pregunta qué es algo no pasa por el reconocimiento de atributos propios o intrínsecos, atribuibles o inherentes, a ese algo que se busca conocer o definir, sino, más bien, por exponer el modo en el que ese algo es capaz de afectar al sujeto percipiente. El lenguaje, reconocido como convección instrumental que permite comunicar las afecciones exclusivamente restringidas del percipiente, sólo describe o narra el modo en el cual éste se halla dispuesto. Por ello, los cirenaicos desarrollaron una gramática centrada en dar cuenta de las afecciones percibidas por el percipiente cuando percibe algo y no preocupada de hablar de ese algo que es percibido. Zilioli $(2012 ; 137)$ se refiere a la gramática de los cirenaicos en los términos de "behavioural solution" o "a sort of behaviourism", p. 175, contestando la calificación de "convencialistas" que Tsouna, V. (1998), adscribe a los cirenaicos. Más allá de la validez de los calificativos, el hecho es que el tránsito de expresiones lógico-lingüístico como, por ejemplo, "estoy siendo endulzado por un algo o estoy dispuesto dulcemente", propias de la gramática cirenaica, a expresiones como, por ejemplo, "ese algo es dulce" resulta impropio para ellos, en el entendido de que el problema no pasa por una conversión gramatical de voz medio-pasiva a voz activa, sino por poner de relieve que el sujeto percipiente sólo puede limitarse a proferir asertivamente sus propias afecciones privadas valiéndose de convenciones lingüísticas y en ningún caso pretender indicar cómo son en realidad los objetos existentes que las causan. Cfr. Sexto, adv. math. VII 192. La gramática cirenaica dotó de medios expresivos el apotegma délfico. Así, el conócete a ti mismo es un hecho de experiencia que viene narrado desde la perspectiva del sujeto que se conoce a sí mismo, mutatis mutandi, que se percibe a sí mismo. Aristóteles, Met. 1010b31-33, desde otra perspectiva epistemológica, acota que tanto lo perceptible como las sensaciones perceptivas son una afección del sujeto percipiente (sc. de todos los seres animados,

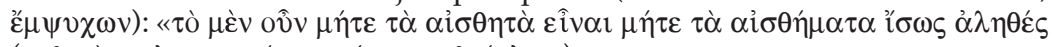

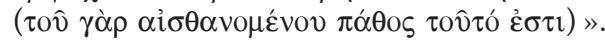

34 Ael., var. hist. IX 20. Ante una tempestad Aristipo justifica su temor y el celo por la vida (ßíov $\dot{\eta} \sigma \pi \mathrm{ov \delta}$ ). Allí viene contrapuesta la noción de una vida miserable y una vida de dicha ( $\pi \varepsilon \rho \grave{~} \kappa \alpha \kappa o \delta \alpha i ́ \mu o v o \varsigma-\pi \varepsilon \rho \grave{~ \varepsilon v ̉ \delta \alpha i ́ \mu o v o \varsigma) . ~}$ Los seguidores de Hegesías, D.L. II 94 señalaban que la $\varepsilon v \delta \delta \alpha \imath \mu$ ví $\alpha$ era un imposible, a saber: i) por la comunión simpatética de alma y cuerpo y ii) por la fortuna. 
continua sucesión de puntos que le otorgan extensión ${ }^{35}$. No se entienda esto como una paradoja zenoniana. De suerte que, si bien es cierto que la sucesión de puntos configuran una línea, tal línea no necesariamente se revelará recta. Semejante replanteamiento no reclamó formulaciones onto-epistemológicas, sino que redimensionando los alcances del apotegma délfico conócete a ti mismo, depositó en el sujeto percipiente la primera certeza, al tiempo que en el movimiento suave su orientación ética: el yo percipiente, tomado en primera persona, percibe teleológicamente cultivando el placer, en singular. La concepción intelectualista de la objetividad da paso a una concepción -digamos- estética de la objetividad.

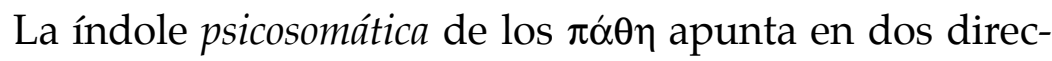
ciones concomitantes. En primer lugar, hace referencia a las afecciones, entendiendo por éstas todo cuanto se experimenta o padece. En este sentido, la noción de contacto recíproco es cardinal. En segundo lugar, hace referencia a las pasiones o emociones, como alegría, miedo, ira o tristeza ${ }^{36}$. En este sentido, la noción de modificación de la disposición anímica es cardinal. En ambos casos, los $\pi \alpha ́ \theta \eta$ son, sin embargo, atributos del alma: de un alma pivotada perceptivamente. Parafraseando al Platón de Leyes, Aristipo concedería que el alma deviene principio del movimiento ${ }^{37}$; no obstante, no la postularía

35 Ael., VH., XIV 6. "Aristipo acostumbraba a hablar con formidable fortaleza, exhortaba a los hombres a ni sufrir por las [experiencias] pasadas ni a atormentarse con antelación por [experiencias] venideras: ello es, en efecto,

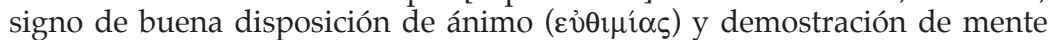

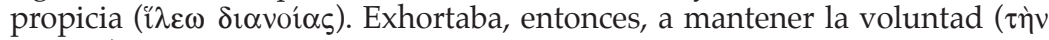
$\gamma \nu \omega ́ \mu \eta v)$ en el día-día, aún más, en aquella parte del día en la cual cada uno ejecuta o piensa algo, pues -decía- sólo el momento presente es nuestro ( efecto, ha muerto, mientras que el segundo se muestra poco claro, si es que acaso llegará". Nótese el paralelo con el testimonio de Ateneo XII 544 en nota 57.

36 Gno. Vat. 743, fr. 83; Plut. De profect. In virt, 9 p. 80, fr. 77; Eliano, VII 3, fr. 76.

37 Pl. Lg. 896b2 y ss. 
exclusivamente semoviente, pues al pivotar en la percepción ciertamente se mueve a sí misma, mueve desde sí, pero i) también es movida y ii) su movimiento no prescinde de la corporeidad $^{38}$. Tal como afirma Aristóteles en Ética a Nicóma-

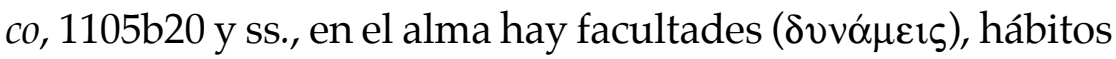

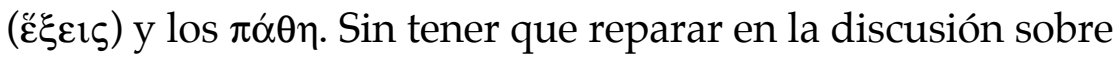
la virtud, vale la pena poner de relieve tres precisiones que hace Aristóteles, pues contribuyen a iluminar el planteamiento de Aristipo, a saber: i) de conformidad con las facultades

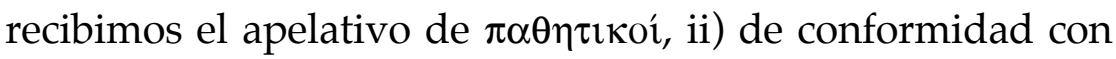
los hábitos nos encontramos bien o mal dispuestos en relación con los $\pi \alpha ́ \theta \eta$ entendidos acá como las emociones o pasiones propias del alma; sin embargo, queda reconocido que iii) a és-

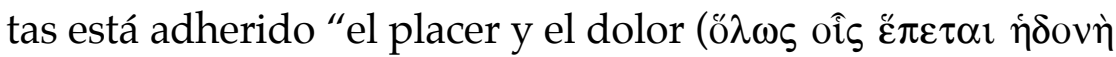

38 (Boys-Stones y Rowe, C., 2013: 126): "It is important, finally, to note that 'body' and 'soul' are used as contrastive terms without prejudice to the question of how the soul is constituted (out of the same elements as the body, or out of some nonmaterial substance?) and whether it survives death [... If we are right in our speculation about Phaedo's strong identification of the soul with the intellect along the lines proposed in the dialogue Plato named after him, then he may have agreed that it is immortal. But other members of the Socratic circle certainly did not agree". Reale, G. (1999: 187,189): "Socrate non poteva svilupare a livello teorético una dimostrazione dell'inmortalità dell'anima [...] Dicevamo che solo Platone sulle basi delle categorie metafisiche scoperte nella sua 'seconda navegazione' potrà procedere alla dimostrazione dell'inmortalità dell'anima. Invece, non solo i Socratici minori ma anche, in generale, gli uomini colti del IV secolo

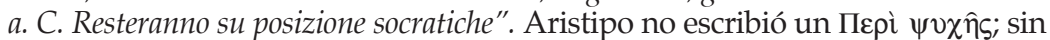
embargo, de la doxografía es posible extraer las siguientes características de su concepción del alma: i) el alma es aliento vital, particularísimo y propio de cada individuo; ii) su existencia queda encarnada en los límites corporales de un cuerpo y no escapa al quehacer y al destino de éste; iii) embellecer el cuerpo no es embellecer el alma y iv) así como el cuerpo entrenado se fortalece, así también el alma, cf. gnom. vat.743, n. 34; D. L. II 71; Anton. Meliss. II 34 \& Stob. III 40, 8. Dos características adicionales pueden ser destacadas. En primer lugar, si nos apoyamos en la concepción de su nieto, Eus., PE., XIV, 18, 32. 764, artífice del replanteamiento de la subjetividad cirenaica, podría defenderse la idea de que también Aristipo hubiese tematizado el alma como una mezcla o compuesto ( $\sigma 0 ́ \gamma \kappa \rho \alpha \sigma ı)$. En segundo lugar, si nos apoyamos en la posición defendida por los seguidores de Hegesias, podría defenderse que también Aristipo hubiera defendido la idea de que el alma es simpatética con el cuerpo $(\sigma \nu \mu \pi \alpha \theta \varepsilon \hat{\imath} v \tau \hat{\widehat{\omega}}$ $\sigma \omega ́ \eta \vartheta \beta \imath \varepsilon \rho \alpha, \mu \alpha \tau \imath)$, esto es, padece en concordancia con y en razón del cuerpo. 
iे $\lambda \hat{v} \pi \eta)^{\prime \prime 39}$. Tanto el primer punto como el segundo -puede decirse- calza plenamente con el planteamiento de los cirenaicos y puede ser naturalmente reconducido a la tesis hedonista central de Aristipo, si adicionalmente tenemos presente la coletilla de Aristóteles al pasaje:

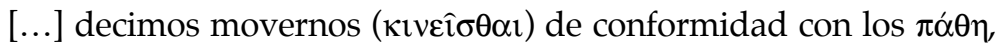
mientras que no decimos movernos de conformidad con las vir-

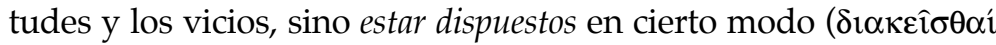
$\pi \omega \varsigma)^{40}$.

El alma, al ser movida de conformidad con los $\pi \alpha ́ \theta \eta$ no se traslada; esto es, no cambia de posición, tampoco aumenta o disminuye, pues no cambia su tamaño y peso. El movimiento

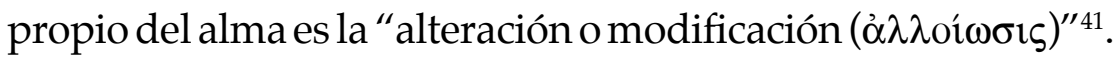
Cuando se habla de alteración o modificación se está haciendo referencia a que el alma percibiendo percibe, a su vez, que está siendo de alguna manera alterada o modificada. Lo que se está poniendo de relieve, en consecuencia, es el carácter reflexivo de la percepción: la percepción en su momento

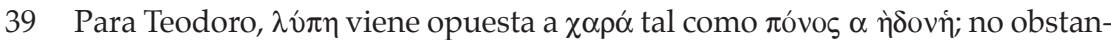
te, postuló los dos primeros como fines y los segundos como intermedios. Con ello, el anclaje cinemático del proyecto de Aristipo es reorientado al colocar el énfasis en el aspecto emocional de la afección.

40 Arist. EN 1106a5-6.

41 Arist. Met. $1069 \mathrm{~b} 3$ y ss. El movimiento del alma podría entenderse en ciertos contextos fisiológicos en términos de generación y destrucción. Si así fuera, esta clave arrojaría luz sobre la discusión del placer. Aclararía especialmente la posición de quienes lo tematizaron, Arist. EN 11754a19 y ss., como génesis. La tesis de Aristipo escapa a esta interpretación por razones más bien dialécticas que fisiológicas, pues así entendido el placer dejaría de ser completo. Postularlo como fin sería admitir que es buscado en vistas de otro, por ejemplo, la felicidad, y ello desvirtuaría la posición hedonista del Cirenaico. Con Bravo (2003: 43-55), podemos afirmar que en el planteamiento hedonista de Aristipo ya está presente lo que en Platón fue paulatinamente evolucionando y configurándose, esto es, el placer comprende una física, una psicología y una fisiología del placer. 
exteroceptivo produce un movimiento interoceptivo del cual

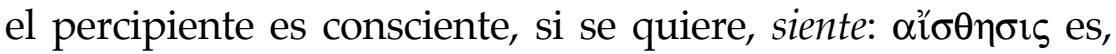
al mismo tiempo, percibir y sentir. El percipiente, por tanto, cuando percibe padece-con-aquello que está dado a ser percibido. Cuando Aristipo señala que el placer es un movimiento suave que se produce en o brota con la percepción está poniendo de relieve, entonces, tanto el momento exteroceptivo como el interoceptivo de la percepción; sin embargo, las fuentes no nos testimonian que él haya acuñado una voz técnica que describiera estas dos caras del percibir. De ello se encargaron los filósofos estoicos y llama poderosamente la atención que a mediados del siglo II d. C. el estoico Hierocles cuando da cuenta de la reflexividad de la percepción animal apele, sin mencionarlos, a expresiones de cuño cirenaico ${ }^{42}$. Probablemente sin proponérselo, Aristipo y los cirenaicos, habrían inaugurado, fruto inicialmente de las discusiones socráticas, la reflexión filosófica en torno a la conciencia de sí. Revelándose internalistas, defensores -diríamos con Sócrates-, del cuidado del alma ${ }^{43}$, se abocaron al conocimiento del mundo sólo en la medida en que éste posibilita el conocimiento de los propios estados afectivo-emocionales a los cuales todo percipiente tiene acceso de forma exclusiva, privilegiada e infalible $^{44}$. El placer del que habla Aristipo se produce en o brota con la percepción una vez que el percipiente al percibir es placenteramente movido, esto es, en tanto que el perci-

42 El epicúreo Colotes, Plu., adv. Col. 1120c-1121e, habría procedido de la misma manera. Su posicionamiento es, no obstante, abiertamente crítico y sin mencionarlos se mofa de las expresiones alambicadas de la gramática cirenaica. En el caso de Hierocles, Col. VI 3 y ss., es distinto, pues las expresiones de los cirenaicos vienen a reforzar la prueba de que los animales se perciben a sí mismos (ver Bastianini, G. y Long, 1992: 268-451; Aoiz, J., Deniz, D. y Bruni Celli, B., 2014).

43 Pl. Ap. 29e2.

44 S. E., M., VII 193-196. 
piente siente que está siendo suavemente alterado o modifica$\mathrm{do}^{45}$. De suerte que ver un atardecer, escuchar un ensamble de metales, oler incienso, beber vino o acariciar un gato no es placentero si el percipiente no se percibe a sí mismo siendo placenteramente movido. La tesis hedonista de Aristipo es disposicional: i) la atención viene puesta sobre las capacidades afectivo-emocionales del percipiente, en su diátesis, o en las facultades -diríamos con Aristóteles- en virtud de las cuales recibimos el apelativo de patéticos y ii) los entes del mundo son placenteramente neutros y sólo eventualmente mueven al percipiente, placenteramente o no, en atención a su propia constitución y nunca en razón de atributos placenteramente intrínsecos al objeto. Así, y como si se hiciera eco de la crítica que en su momento lanzara Jenófanes sobre la imagen cultural de los dioses ${ }^{46}$, Aristipo entiende que el placer no reposa en los entes que por el sólo hecho de ser culturalmente tenidos por placenteros habrían de mover en tal dirección al percipiente. En este sentido, su planteamiento cinemático puede o no acomodarse con lo que culturalmente se tiene por placentero, pero lo cultural no determina el hecho placentero $^{47}$. Por

45 (Damasio, 2010: 196); "The feeling tells me, without a word being spoken, that I own the objects, for the duration, and that I can act on them if I wish to do so. This is, literally, 'the feeling of what happens', the object-related feeling about which I have written in the past. On the matter of feeling in the mind, however, I have this to add: the feeling of what happens is not the whole story. There is some deeper feeling to be guessed and then found in the depths of the conscious mind. It is the feeling that my own body exists, and it is present, independently of any object with which it interacts, as a rocksolid, wordless affirmation that I am alive. This fundamental feeling, which I am not deemed necessary to note in earlier approaches to this problem, Inow introduce as a critical element of the self process. I call it primordial feeling, and I note that it has a definite quality, a valance, somewhere along the pleasure-to-pain range. It is the primitive behind all feelings of emotion and therefore is the basis of all feelings caused by interactions between objects and organism. As we shall see, primordial feelings are produced by the protoself".

46 Xenoph. DK21B14,15,16 \& 34.

47 Teodoro, D.L. II 99 constituye la posición más radical en esta dirección. Por 
ello, ni un atardecer, ni un ensamble de metales, ni el incienso, ni el vino, ni acariciar un gato, es per se placentero. Quizá, por ello, le habrían dicho a Aristipo que sólo a él le era dado vestir con ropas elegantes o con trapos ${ }^{48}$. En cualquier caso, él habría encontrado la forma de sacar placer de una u otra circunstancia indistintamente ${ }^{49}$. Al igual que en su medida también hiciera Sócrates, la posición de Aristipo trastoca, por su parte, los cánones culturalmente establecidos en relación con el placer. Su planteamiento hedonista puede ser visto como un abierto reto a la tradicional concepción ética según la cual quien experimenta placer se esclaviza y da muestras de ser éticamente bajo y débil ${ }^{50}$. Dos anécdotas pueden ser traídas a colación para ilustrar cómo Aristipo, contrastando la concepción cultural del placer, logra redefinir la correcta actitud ética frente al placer, al menos desde la óptica cirenaica. En la primera lo encontramos respondiéndole a un joven que se ruborizaba por verle entrar en casa de una hetera: "el entrar no es vergonzoso, dijo, sino el no ser capaz de salir"51. En la segunda encontramos su célebre sentencia "poseo a Lais pero

ello, quizá, fue expulsado de Atenas, D.L. II 102. Los discípulos de Hegesias, por su parte, señalaban, D. L. II 94. que los ricos o los pobres no experimen-

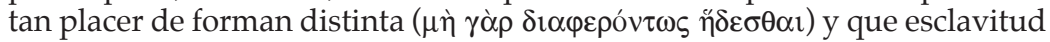
y libertad, tal como el buen o mal linaje o la buena o mala fama son indife-

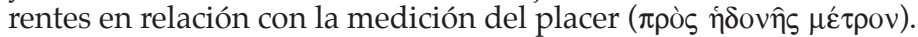

48 D.L II 67.

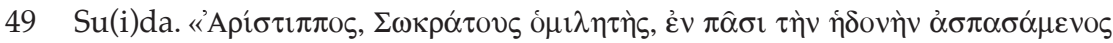

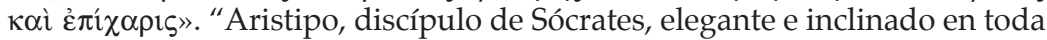
circunstancia al placer".

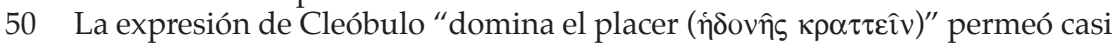
en su totalidad la aproximación ética al tema del placer. Por otra parte, en

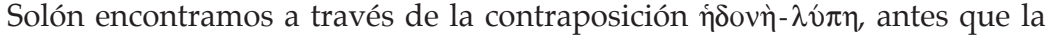
referencia a placeres mixtos, una pincelada del problema de la temporalidad y el placer: "huye del placer que produce aflicción-dolor". En Periandro, por su parte, encontramos la determinación y contraposición entre placer y virtud: "los placeres son mortales, las virtudes, en cambio, inmortales".

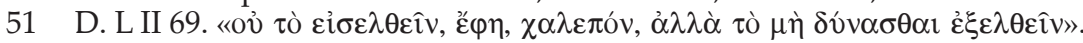


no soy poseído" 52 . En ambos casos viene puesto en evidencia la reinterpretación que efectúa Aristipo al tema del dominio del placer. Su planteamiento hedonista constituye un giro ético en tanto que la vía para encarar el problema ético tradicional del dominio del placer no es la abstinencia como muestra de autodominio, sino, por el contrario, el uso ( $\tau$ ò $\chi \rho \hat{\eta} \sigma \theta \alpha \imath)$ como auténtico dominio y autodominio. En virtud de lo cual señala Aristipo:

Domina el placer no quien se abstiene, sino quien, sirviéndose [de él], no se deja llevar por un sentimiento desordenado. Del mismo modo como también [domina] la nave y el caballo no quien no se sirve [de ellos], sino quien [los] conduce hacia donde quiere ${ }^{53}$.

Ahora bien, volviendo sobre el tercer punto del pasaje de Aristóteles, es necesario notar que la posición cirenaica, con la marcada excepción de Teodoro ${ }^{54}$, tendió a oponer $\pi$ óvos, esfuerzo-dolor ${ }^{55}$, al placer, y no el tradicional $\lambda \hat{v} \pi \eta$ que, si bien puede entenderse como dolor, no obstante, es propiamente una emoción en el contexto del Cirenaico: la aflicción ${ }^{56}$.

52 Ésta es, quizá, una de las sentencias más destacadas por la doxografía. D. L. II 75 et alia.

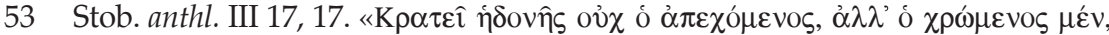

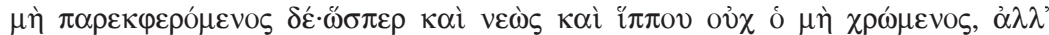

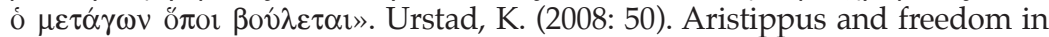
Xenophon's Memorabilia. Praxis, Vol. 1 (2), 41-55. "He appears to transform what we might view as the Socratic principle of self-control over the desire for pleasure into control within the pleasure; or, put somewhat more broadly, he seems to convert what Socrates might as the life of moderation and even restrain into the art of moving correctly within the life of pleasure".

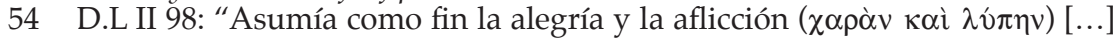
como intermedios, en cambio el placer y el esfuerzo-dolor ( róvov)".

55 Véase n. 33.

56 Ael., VH. VII 3. “Aristipo, a unos compañeros suyos que se lamentaban, les 
La aclaración terminológica permite contraponer al interior del círculo socrático la posición de Antístenes con la de Aristipo, pues Antístenes, quien hizo del esfuerzo el camino a la virtud, asumió un planteamiento antihedonista: es célebre su expresión "antes loco que regocijarme en el placer" ${ }^{57}$. Su posición, en el mejor de los casos, admitía ciertos placeres si venían acompañados de esfuerzos. Defendió -digamos- el placer como recompensa o satisfacción que resulta de y acompaña a los esfuerzos, pero ni entendió el placer como bien, por tanto, no lo vio como fin humano, ni lo concibió temporalmente antecedente al esfuerzo ${ }^{58}$. Aristipo, por el contrario, mostrándose capaz de adaptarse al lugar y a la ocasión ( $\tau$ ó $\pi \omega$

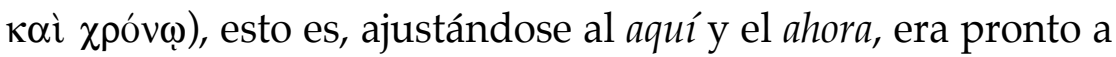
“disfrutar el placer de las ocasiones presentes ( $\tau \hat{\omega} \nu \pi \alpha \rho o ́ v \tau \omega \nu), \mathrm{y}$

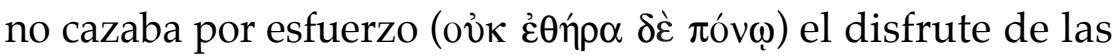
que no están presentes ( $\tau \hat{\omega} \nu$ ov̉ $\pi \alpha \rho o ́ v \tau \omega \nu)^{\prime \prime 59}$. El énfasis que

dirigió severas palabras y algunas otras para mitigar $s u$ aflicción $(\lambda \hat{\pi} \pi \eta \varsigma)$, pero como preámbulo éstas: "en lo personal, yo vengo ante ustedes no con la intención de afligirme con ustedes ( $\sigma \nu \lambda \lambda v \pi \circ v ́ \mu \varepsilon v o \varsigma)$, sino para hacer cesar vuestra aflicción ( $\lambda v \pi v \mu \varepsilon ́ v o v \varsigma) "$. La anécdota deja entrever el estilo argu-

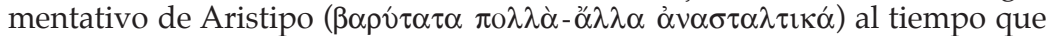
su firme negativa a compartir aflicciones, pues su misión es hacerlas cesar. En consecuencia, dado el planteamiento dicotómico de los cirenaicos, si no se experimenta aflicción-dolor $(\lambda \hat{v} \pi \eta)$, el estado afectivo-emocional opuesto

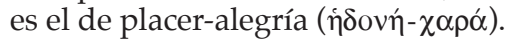

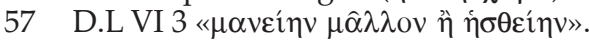

58 (Decleva, 1966: 116). "Non è facile ricostruire con precisione il pensiero antistenico sul piacere; egli accettava quello che sorge dallo sforzo: si può in tal caso considerarlo una forma di à $\lambda v \pi i \alpha$ ed attribuirgli la teoria che Platone espone nel Filebo 43d ss? [...] L'incerteza rimane, dato lo stato delle fonti. Sussisteva, a quanto risulta da questi frammenti, l'accettazione dei piaceri conquistati rettamente oppure in modo paradossale: un esempio chiarificatore è offerto da Xen. Symp. IV $34 \mathrm{ss}^{\prime \prime}$. Wolfsdorf (2013: 19) entiende que la posición de Antístenes debe ser delineada en términos de "kinds of pleasure or between conditions of pleasure".

59 D.L II 66. La anacreóntica XL celebra poéticamente el apego a la temporalidad que la doxografía transmite como marca característica de la actitud de Aristipo. "Puesto que fui hecho mortal/para caminar el camino de la vida/llegando a reconocer el tiempo transcurrido/desconozco, en cambio, el que tengo por recorrer/Dejadme, preocupaciones/Nada tenga yo que ver con ustedes/ 
pone Aristipo en la temporalidad permite acotar aún mejor el hecho de que el movimiento que viene señalado como fin humano esté pivotado en la percepción: en su alcance exteroceptivo la percepción está comprometida con lo presente, pues se percibe lo que está dado a ser percibido ${ }^{60}$. Se sigue, entonces, que propiamente el placer, al brotar con la percepción, sólo tiene como condición de posibilidad el presente ${ }^{61}$. El planteamiento esfuerzo-presente deviene luego placer-futuro, aun cuando fisiológicamente válido, dialécticamente es inválido en el planteamiento de Aristipo. A los cirenaicos, en consecuencia, no les resultó extremadamente difícil conceptualizar la placentera visión de vida de Aristipo y extraer de ella las dos tesis insignia del hedonismo cirenaico, a saber:

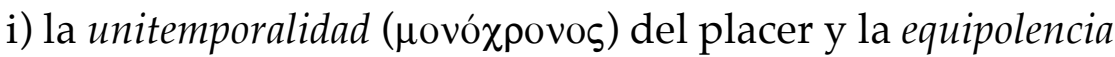
de los placeres ${ }^{62}$. La primera tesis hace referencia a que todo placer es placer percibido mientras el percipiente se percibe placenteramente modificado, las evocaciones prospectivas o las rememoraciones quedan fuera del hecho placentero:

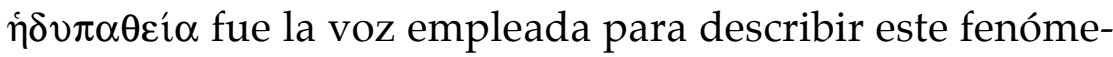

Antes de que me llegue el final/jugaré, reiré y bailaré/ en compañía del bello Lieo". Introduzco ligeros cambios en la traducción de Guichard (2012: 113).

60 (Damasio, 1999: 16): "The simplest kind, which I call core consciousness provides the organism with a sense of self about one moment -now-and about one place-here. The scope of core consciousness is the here and now [...] There is no elsewhere, there is no before, there is no after. On the other hand, the complex kind of consciousness, which I call extended consciousness and of which there are many levels and grades, provides the organism with an elaborate sense of self -an identity and a person, you or me, no less-and places that person at a point in individual historical time, richly aware of the lived past and of the anticipated future, and keenly cognizant of the world beside it". Cfr. Arist. EN 1174b14-20.

61 Wolfsdorf,(2013:22),catalogaelhedonismodeAristipocomopresentisthedonism. Mutatis mutandis, en Aristóteles también encontramos este enfoque, Arist. EN 1175a4-6, reconociendo, sin embargo, que el planteamiento de Aristóteles i) no es hedonista, ii) el placer no es movimiento, sino perfeccionamiento de la actividad y iii) establece jerarquías ético-epistemológicas en los placeres.

Athen. XII 544 \& D.L. II 87. 
no ${ }^{63}$. La segunda tesis enfatiza que no existe diferencia de un placer a otro, por lo que, en consecuencia, tampoco alguno es más placentero que otro. Las posibles diferencias apreciativas fundadas en la intensidad de los placeres no modifican la estructura cinemática del hecho placentero ${ }^{64}$.

La tensión placer-esfuerzo tiene implicaciones no sólo individuales sino también sociales. Por ello, por ejemplo, Aristóteles incluye la denominada vida del deleite

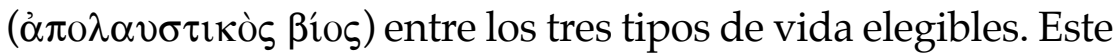
tipo de vida está asociado a la mayoría y al ser descrita como

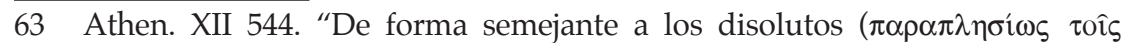
ó $\sigma \omega ́ \tau$ ors), al considerar (sc. Aristipo) que ni la rememoración de los deleites

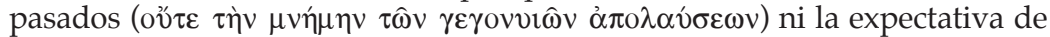

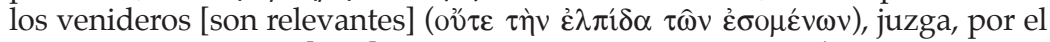
contrario, que el bien [está] en un único momento presente ( $\alpha \lambda \lambda^{\prime} \dot{\varepsilon} v i$ róv $\dot{\alpha} \gamma \alpha \theta \grave{v} v \tau \hat{\omega} \pi \alpha \rho \operatorname{có} \tau \imath)$; estima, pues, que en absoluto [es relevante] el haberse deleitado con y el estar por deleitarse con: el primer [momento] ya no existe

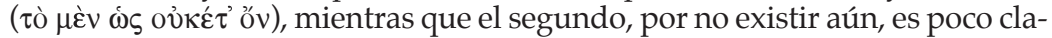

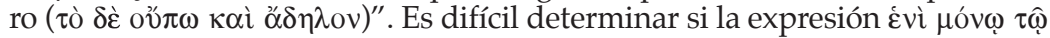
$\pi \alpha \rho o ́ v \tau \imath$ fue o no empleada por el propio Aristipo; en cualquier caso, puede señalarse, sin embargo, que desde un punto de vista semántico, la voz $\mu$ ovó-

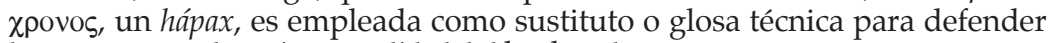
la misma tesis: la unitemporalidad del hecho placentero. La voz i் $\delta v \pi \alpha \theta \varepsilon i ́ \alpha$ merece una puntualización. El verbo $\pi \alpha ́ \alpha \chi \omega$ y sus derivados, al ser modificados por un adverbio deviene una locución adverbial, ejemplos de ello serían $\varepsilon \hat{v}$

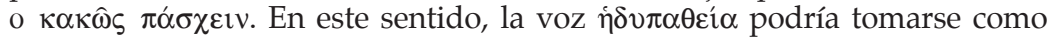

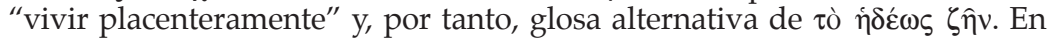
este contexto, no obstante, pongo el énfasis en lo unitemporal para describir el instante en el cual el percipiente siente que está siendo placenteramente movido, si se quiere, se siente viviendo placenteramente en único momento presente. En el Filebo, 21c1 y ss. Platón discute qué papel juega la memoria en el hecho placentero.

64 D.L. II 87. “No difiere un placer de otro, tampoco hay [hecho] más placente-

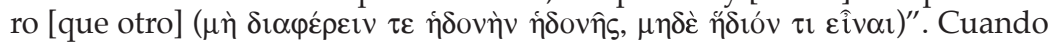

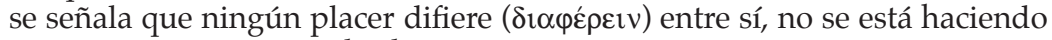
referencia al origen del hecho placentero que, al pivotar en la percepción, puede involucrar uno o más órganos de los sentidos. Lo que se intenta señalar es que la estructura cinemática es idéntica, a saber: movimiento suave.

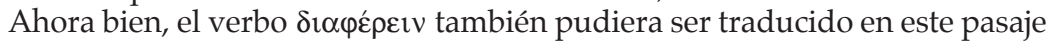
como "ser superior". Si así se hiciera, se estaría destacando, más bien, la estructura evaluativa del hecho placentero, a saber: ningún placer está por encima de otro, esto es, ninguno es un bien superior a otro. 


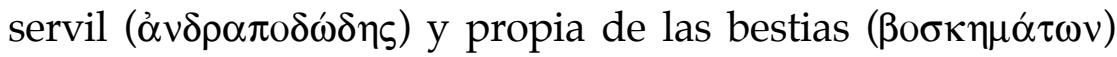
viene despachado ${ }^{65}$. No por ello-huelga decir-deja de ser un estilo de vida a ser elegido. El asunto no es trivial. Rescataré del anecdotario historiográfico dos testimonios a fin de presentar de forma preliminar y sucinta las implicaciones sociales vinculadas al estilo gaudenter de vida que profesó Aristipo, pues aun cuando no perseguiré exhaustividad al abordar el par de testimonios, ambos contribuirán, sin embargo, a la posterior dilucidación del adjetivo suave ( $\lambda \varepsilon \hat{\imath}$ ş) que está empleado en la definición de placer defendida por Aristipo. Así, la dimensión ético-política del placer permitirá clarificar aún con mayor precisión el alcance estético-epistemológico de la definición al tiempoquepondráenevidencialascorrespondenciasexistentes entre el estilo de vida y las consideraciones filosóficas que contribuyeron al apuntalamiento del planteamiento hedonista de Aristipo. Relata Diógenes, en primer lugar, que Aristipo, al ser interrogado respecto a en qué aventajan los filósofos, dijo, "si fueran abolidas todas las leyes viviremos del mismo modo

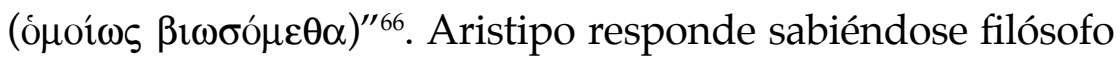
y no precisamente mayoría. Más allá de esto, la anécdota deja

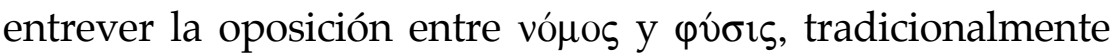
adjudicada al movimiento sofista, aun cuando en su origen se ha de ver a Demócrito ${ }^{67}$. Sin leyes no hay polis. ¿En qué sentido, entonces, los filósofos seguirían viviendo del mismo modo? ¿Cuál es el modo filosófico de vivir, es decir, en qué sentido se habla del mismo modo de vivir con o sin leyes?

65 Arist. EN 1095b17. Sócrates en el Gorgias 494a3, le pregunta a Calicles: “¿Acaso, dado estos dos tipos de vida (sc. la vida del insaciable e intemperante y la vida del moderado), dices que la del intemperante es más feliz que la del moderado (

66 D.L II 68 \& Ps. Hesych. Mil. P. 2, 18.

67 Democr. DK 68A49 \& 68B125. (Vlastos, 1945: 578-592). 
Jenofonte, en segundo lugar, que reconoció en Aristipo

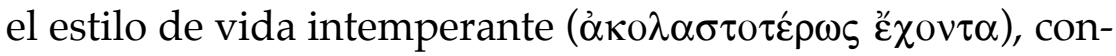
feccionó un diálogo entre Sócrates y el cirenaico con el propósito de dejar en evidencia la inconsistencia doctrinal del discípulo frente al maestro ${ }^{68}$. Sin entrar a reivindicar la historicidad de la conversación, el diálogo es pedagógico y viene a lugar ${ }^{69}$. La conversación gira en torno a cómo habrían de ser educados dos jóvenes, pregunta Sócrates a Aristipo, uno para ser capaz de ejercer el gobierno y otro que en absoluto lo busca. Al margen de este conversatorio, la historiografía da cuenta de la importancia de la paideia en el proyecto filosófico del de Cirene ${ }^{70}$. A tal punto tuvo importancia que pudo haber

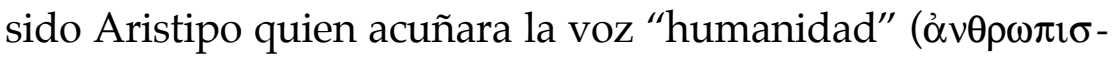
$\mu$ ós): "mejor ser mendicante -nos transmite Diógenes- que no educado; los primeros, en efecto, carecen de bienes, los segundos, en cambio, de humanidad"71. En el texto de Jenofonte, sin embargo, la educación es discutida con miras a su función política. Cuatro son las principales tesis que expresa Aristipo a lo largo de la conversación con Sócrates, a saber: i)

68 X. Mem. II 1,1-14.

69 Urstad, K., art. cit. pp. 45-46, n. 14.

70 Conforme al catálogo que reporta Diógenes, D.L. II 83, Aristipo escribió una obra Sobre la educación.

71 D.L. II 70: "es mejor ser pedigüeño a ser ignorante; pues, unos carecen de bienes, mientras que los otros de humanidad ( $\alpha v \theta \rho \omega \pi \imath \sigma \mu \mathrm{ov})$ ". Aun tomando en consideración las reservas de G. Giannantoni (1958: 54), en lo que respecta

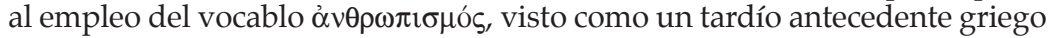
del término latino humanitas, y, siendo conscientes de lo difícil que es precisar con exactitud las dimensiones que tendría este término en la filosofía de Aristipo, se ha de señalar, no obstante, que el contraste perseguido por la anécdota es el de poner en evidencia no sólo la diferencia sustancial entre conocimiento y dinero, sino también la de resaltar la incidencia relativa y, si se quiere, superflua, del dinero al momento de adquirir -permítaseme la expresión- humanidad. Es por ello que los filósofos van a las puertas de los ricos, para adquirir bienes, conscientes de que eso es lo que necesitan, pero los ricos, teniendo bienes, carecen de humanidad para acudir donde los filósofos. 
"no me coloco, dice, en la fila de los que quieren gobernar"72, ii) "me alisto con los que quieren vivir de la manera más ali-

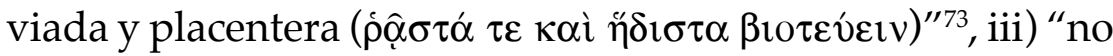
me alisto en la esclavitud, me parece que, en cambio, hay un

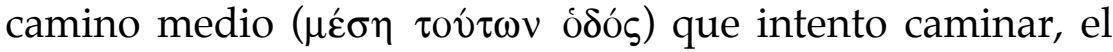
cual ni es por el gobierno ni es por la esclavitud, sino por la libertad ( $\dot{\varepsilon} \lambda \varepsilon v \theta \varepsilon \rho i ́ \alpha)$ "74 y iv) "no me encierro en alguna forma de gobierno $(\pi \circ \lambda \imath \tau \varepsilon i ́ \alpha)$, por el contrario, soy extranjero

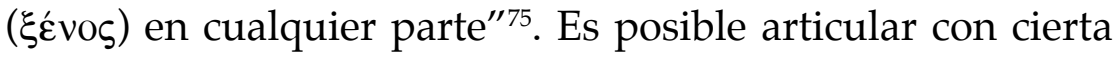
armonía cada una de las tesis que Jenofonte pone en boca de Aristipo con los restantes testimonios doxográficos. Me limitaré, no obstante, a mostrar la congruencia de estas cuatro tesis entre sí y su relación con el modo filosófico de vivir, haya leyes o no. Con ello, a su vez, quedará puesto en evidencia en qué medida el estilo gaudenter de vida con el que la tradición ha revestido a Aristipo es tan sólo un elegante y lujoso ropaje, sin más, el aspecto exterior con el que a posta se adornó el primer filósofo hedonista de occidente a riesgo de ser combatido y olvidado. Esto último, sin embargo, poco pudo turbarlo, dado el carácter íntimo-subjetivista y permanentemente anclado al presente de su filosofía.

El núcleo de articulación está depositado en el concepto de $\dot{\varepsilon} \lambda \varepsilon v \theta \varepsilon \rho i ́ a$, visto por Aristipo como el camino medio que confiesa caminar $(\beta \alpha \delta i \zeta \varepsilon \imath v)$. Concordia y amistad son los componentes mínimos para articular, según dice Sócrates a

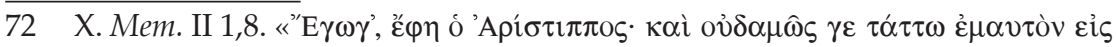

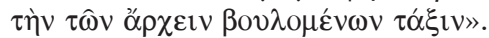

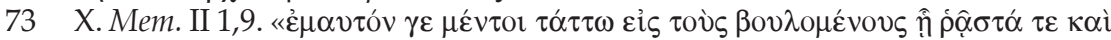

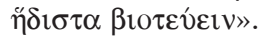

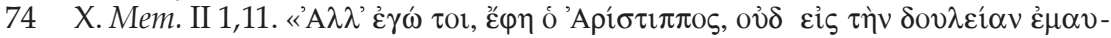

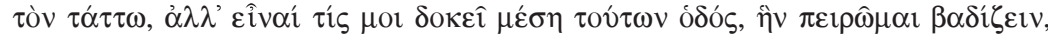

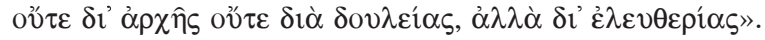

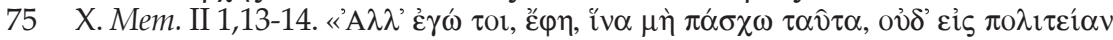

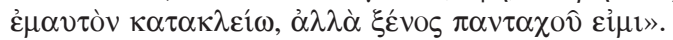


Trasímaco $^{76}$, cualquier comunidad con arreglo a la justicia.

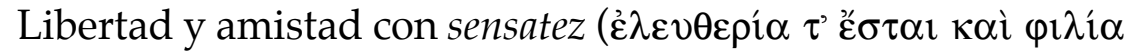
$\mu \varepsilon \tau \grave{\alpha}$ $\rho \rho v \eta ́ \sigma \varepsilon \omega \varsigma)$, por su parte, afirma el ateniense en Leyes 603e, son necesarios para que una polis se halle bien gobernada. Allí, al comparar la monarquía, forma de gobierno Persa, y la democracia, forma de gobierno de los atenienses, la esclavitud viene contrapuesta a la libertad que, inserta en la dinámica gobernante-gobernado, se la entiende junto con la amistad y la comunión de pensamiento como el elemento propiciador del avance o progreso de la polis ${ }^{77}$. En ausencia de estos elementos, la polis se destruye y ello ocurre cuando el gobernante en absoluto se ocupa de la recta

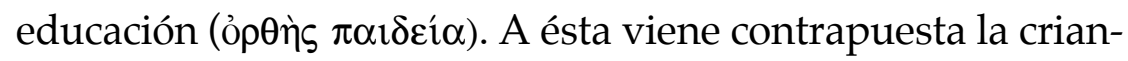

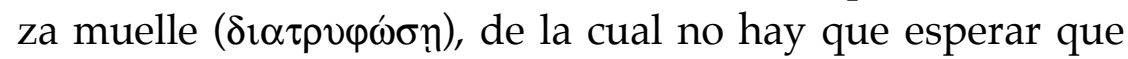
surja niño, varón o anciano que sobresalga por la virtud ${ }^{78}$. El pensamiento de Aristipo es diametralmente opuesto a esta concepción de Platón. Para él la libertad no está inserta en la dinámica gobernante-gobernado, no la entiende políticamente, en el sentido restringido del término. La entiende, por el contrario, estando al margen de esta dinámica y en razón de ello, consecuentemente, él se define no ciudadano sino extran-

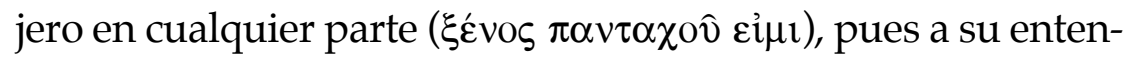
der se trata de ser "libre de" y no "libre para"79.

76 Pl. R. 351d.

77 Pl. Lg. 694 b6 y ss.

78 Pl. Lg. 696a2 y ss..

79 Así como el concepto de libertad vine entendido fuera de la esfera de lo político, otro tanto sucede para Aristipo con el concepto de esclavitud. Aristóteles, Pol. 1253a27, señala que "quien no es capaz de vivir en comunidad o quien a causa de su autosuficiencia no está necesitado de ello, [ése] en absoluto es parte de la polis, de suerte que o es una bestia o es dios" (Taylor, 1979: 113-128). "I take Aristippus as emblematic for my argument in this article for a cluster of reasons, all related to the fact that he is a 'part' who (viciously enough) feels to seem no need to be incorporated into the 'whole' [...] Aristippus helps us understand that modern liberal sympathy for apolitical ideas is 
El poeta Mimnermo ya se había manifestado más o menos próximo a esta especie de "cosmopolitanismo inverso" de Aristipo en el que se reniega de cualquier adhesión o pertenencia a una comunidad, y se enaltece la interioridad como única realidad digna de ser atendida ${ }^{80}$.

Alegra a tu corazón, pues entre crueles ciudadanos, alguno hablará mal de ti y algún otro lo hará en mejores términos ${ }^{81}$.

Al renunciar a gobernar o ser gobernado, Aristipo abandonaría la correcta educación de la cual habla Platón y en la cual seguramente fue educado, con el firme propósito de transitar un curso de vida aliviado y placentero, esto es, gaudenter: ésta viene a ser la respuesta del cirenaico a la pregunta cómo se debe vivir. El camino medio que camina Aristipo, aun cuando fue entendido como vida muelle, no se halla, sin embargo, alejado de la noción de excelencia-virtud ${ }^{82}$, sino que ésta viene entendida en términos de dominio y autodominio en permanente apego a las circunstancias presentes:

based not so much in philistinism and superficiality of attitude as on specific set of historical transformations -structural changes which eventually made it unrealistic to conceive of Western societies as civic wholes made out of citizen parts". Aristipo fue el primer filósofo hedonista de occidente y, salvando el anacronismo, pudiera también verse como el primer liberal. En cualquier caso, se ha de tener presente que su posición -digamos- reactiva las concepciones holísticas báscula sobre pilares íntimo-subjetivistas que encontraron en el hedonismo y la libertad negativa sus manifestaciones tanto éticas como políticas.

80 Entre Platón y Aristipo encontraríamos a Antístenes, Stob. anthol. IV 4, 28, defendiendo una posición utilitarista. "Al ser interrogado acerca de qué modo uno podría acercarse a la participación política ( $\pi$ o $\lambda \imath \tau \varepsilon i ́ \alpha)$, dijo, de la misma manera que [uno se acerca] al fuego, ni demasiado cerca para no quemarse, ni muy lejos para no pasar frío".

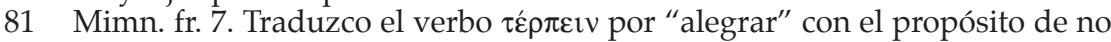
asimilarlo a la voz "placer o complacer" y así evitar confundirlo con la voz $\eta ๊ \delta \varepsilon \sigma \theta \alpha l$; no obstante, en algunos contextos esta voz, al igual que $\chi \alpha \rho \varepsilon \hat{\imath} v$, suele traducirse como términos sinónimos a ๆ̋ $\delta \varepsilon \sigma \theta \alpha$ l.

Véase n. 23. 
en el uso o el trato ( $\tau$ ò $\chi \rho \hat{\eta} \sigma \theta \alpha \mathrm{l}$ ) con las cosas se evidencia la excelencia-virtud propia de cada individuo se esté perfumado o coronado. Es por ello que al ser preguntado qué sacó de la fi-

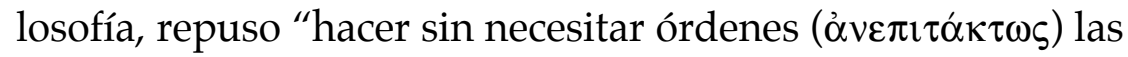
cosas que algunos hacen por miedo a las leyes" ${ }^{\prime 83}$ : el filósofo legisla para sí sin perseguir arreglo con la legislación de la polis.

El modo gaudenter de vida que propone Aristipo prescinde de constricciones, sean leyes o temores, pues estas coacciones representan un impedimento para la libertad que exige, por el contrario, un carácter pleno de confianza $(\theta \alpha \rho \rho o v ́ v \tau \omega \varsigma)^{84}$, con el cual es posible reconocer, en permanente atención a las circunstancias presentes, que el movimiento suave es el fin humano, trátese incluso de un esclavo, políticamente hablando. La libertad de la que habla Aristipo no es una condición propia de lo político sino propia del individuo. De suerte que, el tener o no libertad política no es un impedimento al momento de experimentar placer $^{85}$. En relación con esto, puede ser señalado a modo de consejo práctico lo que se desprende de la anécdota sobre Aristipo y un siervo que se sentía oprimido cuando transportaba dinero por el camino: "deja caer

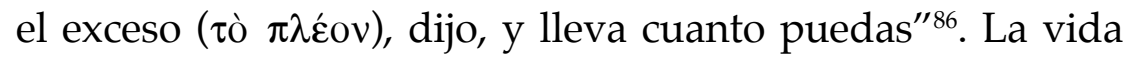
más placentera y aliviada, descrita como movimiento suave, en el exceso encuentra impedimento, al menos así es asumido en el planteamiento del cirenaico, aun cuando una de las características propias con las que viene asociado el placer en otros contextos filosóficos es propiamente el exceso. Aris-

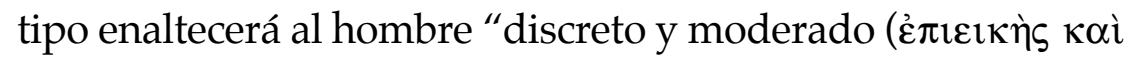

83 Excerpta e Ms. Flor. Joan Damas. II 13, 146. Cfr. Pl. Ep. VII 337a y ss.

84 D. L. II 68. "Al ser preguntado acerca de qué ha obtenido de la filosofía, dijo, el poder tratar con plena confianza con todos".

85 Véase n. 48.

86 D.L II 77. «ỏं 
$\left.\mu \varepsilon \dot{\varepsilon} \tau{ }^{\prime \prime} \varsigma\right)^{\prime \prime 87}$ y entiende, por su parte, que al estar libre del exceso se da el movimiento suave, dado que en su planteamiento no existen placeres mixtos, menos aún, verdaderos o falsos, en razón de lo cual sus seguidores asumieron que cualquier impedimento al movimiento suave, esto es, al placer, ha de

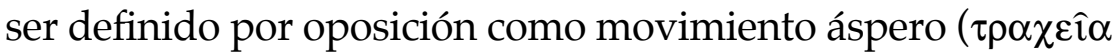

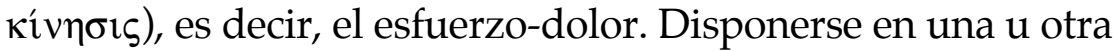
dirección es cuestión de elección o evasión, si se quiere, de selección ${ }^{88}$. Un testimonio de Plutarco ilumina muy claramente este proceso de selección valiéndose de un ejemplo que describe también a través del movimiento cómo se da o no la orientación al placer: "la mayoría yendo más allá de las fronteras de las cosas útiles y potables relativas a uno ( $\tau \grave{\alpha} \chi \rho \eta \sigma \tau \grave{\alpha}$

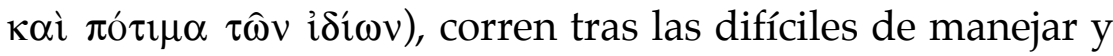
perversas $(\tau \grave{\alpha} \delta v \sigma \chi \varepsilon \rho \hat{\eta} \kappa \alpha \grave{\imath} \mu \mathrm{o} \chi \theta \eta \rho \grave{\alpha})^{\prime 89}$. Mientras la mayoría corre ( $\tau \rho \varepsilon ́ \chi o v \sigma \imath v)$, diríamos contrastando este pasaje con el de Jenofonte, Aristipo intenta caminar $(\pi \varepsilon \imath \rho \hat{\omega} \mu \alpha \imath \beta \alpha \delta i \zeta \varepsilon \imath v)$. La diferencia salta a la vista no sólo en razón de la intensidad del movimiento, sino y, más importante, en razón de la orientación del movimiento. Así, la mayoría se mueve en dirección al gobierno o la esclavitud, catalogables como cosas difíciles de manejar y perversas, mientras que Aristipo, no yendo más allá de lo que le pertenece o es relativo a uno ( $\tau \hat{\omega} v$ i $\delta i ́ \omega v)$, intenta un camino medio que, mostrándose útil y potable, representa un modo más aliviado y placentero de vida. El adjetivo potable, puesto en relación con lo que es relativo a cada uno, fue usado con anterioridad por Heráclito ${ }^{90}$ al hablar de la misma agua para los peces y los hombres. Acá he querido mantener la idea

87 Stob. anthl. III 37, 24.

88 S. E. M VII 11.

89 Plu. de tranq. anim. p. 469c.

90 Heraclit. DK22B61. 
de potable, aun cuando en otros contextos el adjetivo puede sencillamente significar placentero.

Ahora bien, propiamente el adjetivo "suave", empleado por Aristipo para describir la objetividad del hecho placentero, está fundamentalmente asociado al tacto. Así, viene usado en la Ilíada al momento de describir una superficie lisa, por ejemplo, un tronco ${ }^{91}$. Aún más relevante para la definición de Aristipo es Odisea 7, 282, pues allí Odiseo, náufrago en Ogigia, la isla de Calipso, al momento de abandonarla se topa

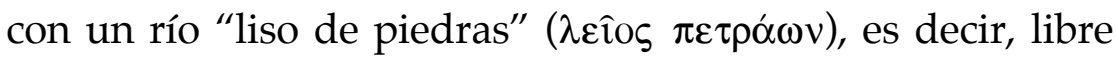
de éstas ${ }^{92}$. Heródoto, por su parte, emplea el adjetivo para referirse a la mar y describirla suave o seren $a^{93}$. Estos pasajes suministran algunas de las características que permiten acotar aún mejor el alcance del adjetivo suave en la definición de Aristipo $^{94}$. En primer lugar, arrojan luz en torno a la elección de un adjetivo asociado al tacto, pues al postular la capacidad sensoperceptiva como propiciadora del hecho placentero, el tacto representa el órgano más extendido de los sentidos y poseedor de mayor y más elemental capacidad informativa que los restantes ${ }^{95}$. En segundo lugar, el contexto marítimo, pues bien se sabe que el nieto de Aristipo al reformular el planteamiento hedonista de su abuelo postuló tres estados afectivo-emocionales apelando a los estados del mar para describir cada uno de éstos, a saber: i) el dolor como tempestad, ii) el placer como onda-suave o viento favorable y iii) un estado intermedio entre el dolor y el placer en términos de

\footnotetext{
91 Hom. Il. IV 484.

92 Hom. Od. 7282.

93 Hdt. II 117, 6.

94 Cfr. Pl. Crat. 408d2.

95 Con Cicerón, Lucullus, 20, también diríamos que la percepción en su momento inetroceptivo se vale del tacto. En este caso se estaría haciendo referencia al tactus intimus.
} 
calma marina ${ }^{96}$. Por su parte, la noción de movimiento, entendida como alteración o modificación, también está ligada al tacto. Esta conjunción de factores permite poner de relieve dos características adicionales del hecho placentero. En primer lugar, la noción de movimiento se opone a la de fijación

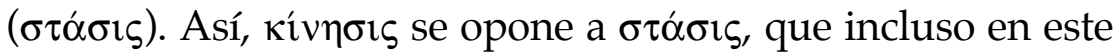
contexto puede llegar a significar, en tanto ausencia de movimiento, propiamente la suspensión de funciones vitales. Vinculado a este hecho se enmarca el debate sobre la distinción taxonómica entre placeres estacionarios ( $\alpha \tau \tau \alpha \sigma \tau \eta \mu \alpha \tau \iota \kappa \alpha i)$ y

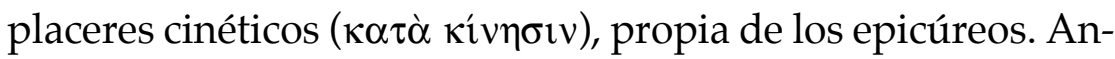
níceris se mantuvo fiel a Aristipo y no validó como placeres la ausencia de dolor ( $\dot{\alpha} \pi$ oví $\alpha$ ) y la imperturbabilidad ( $\alpha \dot{\tau} \alpha \rho \alpha \xi \dot{\xi} \alpha)$, por el hecho de que, siendo éstos estacionarios, no son movimiento ${ }^{97}$. En segundo lugar, todo movimiento genera, sea éste suave o áspero, un cierto tipo de emoción -digamos-afín a las características del movimiento, por lo que, entonces, fisiología y psicología son los dos momentos de los đá $\theta \eta$. Así, entonces, y si bien temporalmente una antecede a la otra, a la afección sigue una emoción.

La filosofía cirenaica no desarrolló una geometría del placer ni una técnica escrutadora del hecho placentero. Su planteamiento, desde Aristipo en adelante quiere subrayar que la objetivad del hecho placentero se palpa. Todo ser con capacidad sensoperceptiva encuentra, entonces, en estos dos movimientos primarios, a saber, el suave y el áspero, el criterio interpretativo a partir del cual orienta un curso de ac-

96 Eus. PE XIV 18, 32 764a.

97 D. L II 89. El estado catastemático es propio del durmiente. 


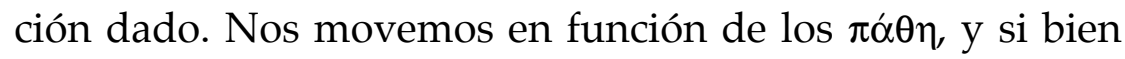
éstos también devienen emociones, como ha sido señalado, el planteamiento cirenaico, sin embargo, no pone de relieve que somos movidos por las emociones, por ejemplo, por la alegría o la ira, sino, antes bien, que sí lo hacemos en función del movimiento, bien suave o bien áspero, que está al origen de la emoción. A través de los $\pi \alpha ́ \theta \eta$ los cirenaicos interpretaron el modo gaudenter de vida que profesó Aristipo. En atención a ello generaron un entramado conceptual orientado a dar congruencia epistemológica al planteamiento hedonista inicial. Los $\pi \alpha ́ \theta \eta$ por tanto, poseen dimensión epistemológica y ética. Ya Cicerón y Sexto se habían percatado de ello. Cicerón, haciéndose eco de la anécdota en la que se narra que Aristipo arrojó al mar el dinero para no perecer por él, llama la atención sobre la dimensión epistemológica y ética de los $\pi \alpha ́ \theta \eta$ en el momento en que entiende que la afección (affectio) "es un cierto cambio en el significado de las cosas en atención al tiempo, al éxito de los empeños, a la conducta, y a la inclinación de los hombres" ${ }^{\prime 98}$. Sexto, por su parte, enmarcado en la discusión en torno al criterio, recalca que para los cirenaicos los $\pi \alpha ́ \theta \eta$ son los criterios y que ellos viven adheridos a éstos. Dos adjetivos emplea Sexto para describir la valencia epis-

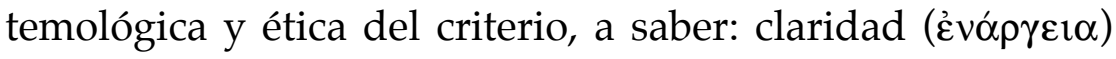

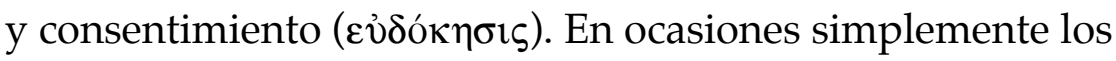
describe como infalibles ( $\dot{\alpha} \delta 1 \alpha ́ \alpha \varepsilon v \sigma \tau o \varsigma)^{99}$.

La preocupación de Aristipo fue la de señalar que el movimiento suave del alma (Epifanio) determina la orientación de un proyecto virtuoso de vida aun incluso si se estuviera fuera de la polis. En este sentido, frente al movimiento áspe-

98 Cicero. de invent. II 58, 176.

99 Sext. adv. math. VII199-200. 
ro, el suave luce como el camino expedito para consumarlo en tanto que al estar "liso de piedras" constituye la perfección o excelencia de dicho movimiento ${ }^{100}$. El planteamiento, entonces, no se centra en eliminar o hacer caso omiso a lo que podríamos denominar adversidades, sino, más bien, en reconocer en la claridad e infalibilidad de los $\pi \alpha ́ \theta \eta$ el baremo interpretativo de las circunstancias presentes, desprovistas éstas de calificativos esenciales. En consecuencia, la filosofía cirenaica hizo de los $\pi \alpha ́ \theta \eta$, esto es, de la índole psicosomática de las propias afecciones, su primera certeza y, a la vez, su imperativo categórico. Su concepción de lo real se configuró

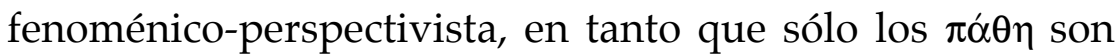
fenómeno y su exclusiva aprehensibilidad sólo se da de forma privada y particular: hay fenómeno y hay perspectivas del fenómeno. La única norma de conducta, por su parte, consiste en permanecer fiel a la claridad e infalibilidad de los $\pi \alpha ́ \theta \eta$, esto es, consentir a ellos. De suerte que, en aras de un curso de vida más aliviado y placentero se ha de perseguir el movimiento suave, diría Aristipo, sea al naufragar o en la corte de Dionisio, pues para cada ocasión y lugar existe un ajuste

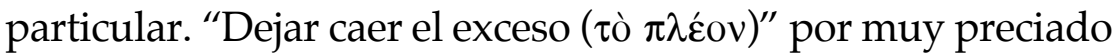
que se tenga el valor de la carga, puede ser tomado a modo de consejo práctico para ello. Una presentación alternativa pudiera ser: "carga con lo que puedas" y no hagas de Atlas.

Aristipo no escribió obra alguna sobre el placer. Dedicó, en cambio, obras a la educación, la virtud y la fortuna. Dedicó una a los náufragos y otra a sus parientes. Quizá a alguna de estas dos últimas pertenece el siguiente pasaje que ejemplifica de forma sintética el planteamiento filosófico de Aristipo y su orientación hedonista.

100 Clem. Alex. strom. II, XXI 127, 1. 
En una ocasión, Aristipo, mientras navegaba, fue arrastrado por las olas a las orillas de Sicilia cuando el casco de su nave quedó destruido. En un primer momento, sintió plena confianza

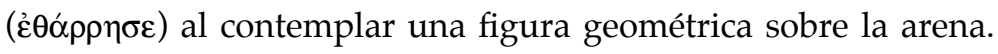
Concluyó, entonces, que había llegado ante griegos y hombres sabios, no ante bárbaros. Luego, habiéndose acercado al gimnasio de Siracusa y exclamando los versos « ¿quién acogerá hoy al errante Edipo con pocos presentes?, algunos se le acercaron y al reconocerlo le ofrecieron de inmediato cuanta cosa necesitaba. Dado que algunos tenían la intención de navegar a Cirene, su patria, se preguntaban si no quería enviar noticias a los suyos. ¿Exhortarlos, dijo, a procurarse las posesiones con las que incluso

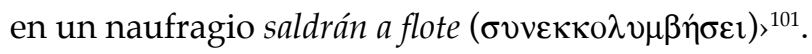

\section{Bibliografía}

Aoiz, J., Deniz, D. y Bruni Celli, B (†). (2014). Elementos de ética, Extractos de Estobeo y Glosas de la Suda de Hierocles el estoico. Edición bilingüe griego-español. Helmantica LXV (193), en prensa.

Bastianini, G. \& Long, A. (1992). Hierocles. Corpus dei papyri filosofici Greci e Latini, I (1), 268-451.

Boys-Stones, G. y Rowe, C. (2013). The Circle of Socrates. Readings in the First-Gerenation Socratics. Indiannapolis: Hackect Publishing Company.

Bravo, F. (2003). Las ambigüedades del placer. Ensayo sobre el placer en la filosofía de Platón. Alemania: Academia Verlag.

101 Galen., exhort, 5. En la misma dirección Excerpta e Ms. Flor. Joann. Damas. II 13, 138. "Aristipo exhortaba a los jóvenes a procurarse las provisiones con

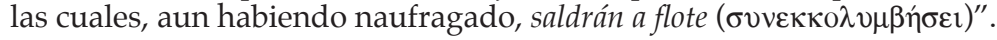


(2002). La teoría platónica de la definición. Venezuela: Fondo Editorial de Humanidades y Educación.

Chiesara, M. (2001). Aristocles of Messene. Testimonia and fragments. Oxford: Oxford University Press.

Damasio, A. (2010). Self comes to mind. Constructing the conscious brain. Nueva York: Vintage Books. (1999). The feeling of what happens. Body and emotion in the making of consciousness. Nueva York: Harcourt Brace \& Company.

Decleva Caizzi, F. (2009). Minor Socratics. En M.L. Gill y P. Pellegrin (eds.). A Companion to Ancient Philosophy. Oxford: Wiley-Blackwell.

Decleva, F. (1966). Antisthenis Fragmenta. Milano: Cisalpino. Giannantoni, G. (1958). I Cirenaici: raccolta delle fonti antiche, traduzione e studio introduttivo. Florencia: Sansoni.

Guichard, L. (2012). Anacreónticas. Madrid: Cátedra.

Guthrie, W.K.C. (1969). A History of Greek Philosophy. The Fifth-Century Elightenment, vol. III, J. Rodríguez Feo (trad.). Madrid: Gredos.

Irwin, T. (2007). The Development of Ethics. A Historical and Critical History. Vol. 1. From Socrates to the Reformation. Oxford: Oxford University Press.

Mann, W-R. (1996) The Life of Aristippus, Archiv für Geschichte der Philosophie, 78(2), 97-119.

Mannebach, E. (1961). Aristippi Cyrenaicorum Fragmenta. Leiden: Brill.

Mársico, C. (2013). Socráticos. Testimonios y fragmentos I. Megáricos y cirenaicos. Buenos Aires: Losada.

Morgado, I. (2012). Cómo percibimos el mundo. Una exploración de la mente y los sentidos. Barcelona: Ariel.

Nozick, R. (1995). Socratic Puzzles. Phronesis(40), 143-155. 
Reale, G. (1999). Corpo, anima e salute. Il concetto di uomo da Omero a Platone. Milán: Raffaello Cortina Editore.

Russel, D. (2005). Plato on Pleasure and the Good Life. Oxford: Oxford University Press.

Tarrant, D. (1932). The Tradition of Socrates. Greece $\mathcal{E}$ Rome, Vol. 1(3), 151-157.

Taylor, S. (1979). Aristippus in and out of Athens. The American Political Science Review, 73(1), 113-128.

Tsouna, V. (1998). The espistemology of the Cyrenaics. Cambridege: Cambridge University Press.

(1994). The Socratic Origins of the Cynics and Cyrenaics. En P. Vander Waert (ed.). The Socratic Movement. Ithaca: Cornell University Press.

Urstad, K. (2008). Aristippus and freedom in Xenophon's Memorabilia. Praxis, Vol. 1(2), 41-55.

Vlastos, G. (1945). Ethics and Physics in Democritus. The Philosophical Review, 54(6), 578-592.

Wolfsdorf, D. (2013). Pleasure in Ancient Greek Philosophy. Reino Unido: Cambridge University Press.

Zayas, M. (2013). Un extranjero en su propia tierra. Aristipo como modelo del ápolis aristotélico. Eidos, 18, 124-147.

Zilioli, U. (2012). The Cyrenaics. Reino Unido: Acumen. 


\section{Resumen}

El tema del placer, entendido propiamente como dimensión psicosomática de los seres animados, fue ampliamente documentado por diversos autores a lo largo de la antigüedad griega. Articular una interpretación unitaria resulta, no obstante, tan complejo como contraproducente. Dos son las razones: i) la variedad de los ámbitos intelectuales en los que el placer fue tematizado o, al menos, evocado; y ii) la diversidad de voces que, empleadas con mayor o menor rigurosidad descriptiva, exhiben algunos aspectos directamente ligados al hecho placentero. El presente artículo persigue arrojar luz sobre la primera filosofía hedonista o, expresado con mayor rigor, sobre el primer filósofo hedonista de la antigüedad: Aristipo de Cirene quien, a diferencia del hedonismo analgésico defendido por Epicuro, abogó por un modo placentero de vida, cinemáticamente fundado, al asumir como fin humano el movimiento suave producido en la percepción ${ }^{102}$.

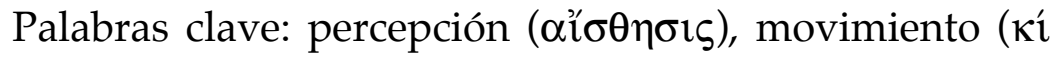

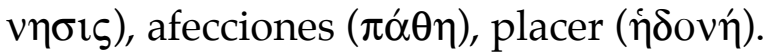

\section{Abstract}

The subject of placer, properly understood as a psychosomatic from animated beings, was widely documented by many authors along the ancient Greece. However, create a singular

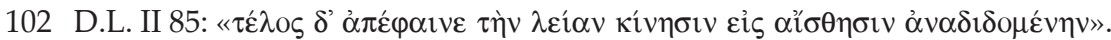
Para la recopilación doxográfica de los testimonios de Aristipo de Cirene y los cirenaicos, véase Giannantoni, G. (1958). I Cirenaici: raccolta delle fonti antiche, traduzione e studio introduttivo. Florencia: Sansoni; y Mannebach, E. (1961). Aristippi Cyrenaicorum Fragmenta, Leiden: Brill. Las traducciones empleadas en el presente trabajo son propias, en caso contrario será indicado. 
interpretation is nevertheless, as complex, as counterproductive. Two are the reasons: 1 ) the several intellectual areas in which the placer was a topic or, at least, evoked, and 2) the diversity of employed voices that, applied with higher or lesser descriptive intensity, shows some directly bound aspects to the pleasurable fact. The current article follows to drop some light over the first hedonistic philosophy or, express with higher precision, about the first hedonic philosopher of the ancient times: Aristippus of Cyrene, who, unlike the analgesic hedonism defended by Epicurus, advocated by a pleasurable way of life, cinematically founded, to assume as human purpose the soft movement produced by perception.

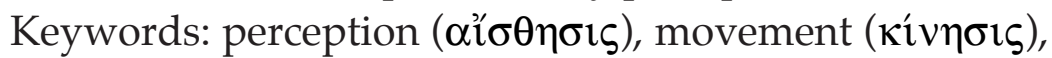

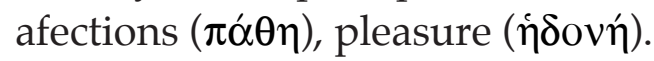

